\title{
Sexual dimorphism in inorganic mercury toxicokinetics and the attendant lipotoxic and non-lipotoxic dyslipidemia in the rat
}

\author{
A.D. Wusu ${ }^{\text {a }}$, O.O. Ogunrinola ${ }^{\text {a }}$, O.K. Afolabi ${ }^{\text {b }}$, E.O. Abam ${ }^{\mathrm{c}}$, D.O. Babayemi ${ }^{\mathrm{d}}$, O.A. Dosumu ${ }^{\mathrm{d}}$, O. \\ B. Onunkwor ${ }^{\mathrm{d}}$, E.A. Balogun ${ }^{\mathrm{e}}$, O.O. Odukoya ${ }^{\mathrm{f}}$, O. Ademuyiwa ${ }^{\mathrm{d}, *}$

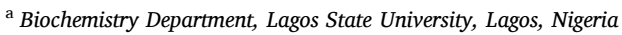 \\ b Biochemistry Department, Ladoke Akintola University of Technology, Ogbomosho, Nigeria \\ ${ }^{\mathrm{c}}$ Chemical and Food Sciences Department (Biochemistry Unit), Bells University of Technology, Ota, Nigeria \\ d Biochemistry Department, Federal University of Agriculture, Abeokuta, Nigeria \\ e Biochemistry Department, University of Ilorin, Ilorin, Nigeria \\ ${ }^{\mathrm{f}}$ Chemistry Department, Federal University of Agriculture, Abeokuta, Nigeria
}

\section{A R T I C L E I N F O}

\section{Keywords:}

Inorganic $\mathrm{Hg}$

Sexual dimorphism

Dyslipidemia

Cholesterogenesis

Phospholipidosis

\begin{abstract}
A B S T R A C T
The influence of variability in the biology of living organisms is poorly appreciated in toxicology. However, multiple lines of evidence indicate that sex-differences modulate toxicokinetics and toxicodynamics from cellular/molecular to whole animal levels resulting in different toxic responses of living organisms to xenobiotics exposure. In order to investigate the influence of sex in inorganic mercury $(\mathrm{Hg}$ ) exposure, male and female Wistar rats were exposed to $0.5,1.0$ and $1.5 \mathrm{mg} \mathrm{Hg} / \mathrm{kg}$ body weight orally as $\mathrm{HgCl}_{2}$ twice a week for 12 weeks. $\mathrm{Higher}$ $\mathrm{Hg}$ levels in the females (except heart) as compared to males were observed in the animals. At the highest dose of inorganic $\mathrm{Hg}$, female renal $\mathrm{Hg}$ content was 3.3 times higher than that of the males. Mixed sexual dimorphism characterised circulating-lipid- and organ-lipid lipotoxic and non-lipotoxic dyslipidemia. The highest dose of inorganic $\mathrm{Hg}$, induced hypercholesterolemia in the males as opposed to hypocholesterolemia in the female. Plasma and erythrocyte free fatty acids increased in both sexes, although the increase was more pronounced in the male. Reverse cholesterol transport was inhibited in the male at the highest dose of Hg, whereas female HDL became enriched with cholesterol. Female erythrocytes had all their lipids increased, whereas only male erythrocyte triglyceride increased. Brain cholesterol and phospholipids, and splenic phospholipids were depleted in both sexes. Our findings indicate that inorganic $\mathrm{Hg}$ exposure appears to affect $\mathrm{Hg}$ and lipid kinetics differently in both sexes, thus underscoring the need to develop sex-tailored approaches in the treatment of metal toxicosis and its metabolic outcomes.
\end{abstract}

\section{Introduction}

The variability in the biology of living organisms is poorly appreciated in toxicology. However, accumulating evidence indicates that the variability in the anatomy, biochemistry, physiology and genetics between male and female modulates toxicokinetics and toxicodynamics from cellular/molecular to whole animal level, resulting in sexual dimorphism in the pathophysiology and clinical expression of various toxic responses of humans and other animals to xenobiotics exposure [1, 2]. In the last two decades, much of our current knowledge of the toxic effects of chemicals on humans was borne out of industrial toxicology and epidemiological studies of workforces exposed to high levels of one or more chemicals. Conventional industrial workforces were highly skewed towards the male sex, with the female often absent or in small numbers such that they were often excluded from such studies $[3,4]$. Given the widespread entry of the female sex into various anthropogenic activities in developed and developing economies underscores the need to fill existing gaps in knowledge about toxic responses on exposure of female and male to old and new industrial/occupational and environmental chemicals [1].

Mercury is a toxic metal whose history dates back to antiquity. It is a ubiquitous and pervasive environmental toxicant that exists in three

\footnotetext{
* Corresponding author.

E-mail addresses: adedoja.wusu@lasu.edu.ng (A.D. Wusu), olabisi.ogunrinola@lasu.edu.ng (O.O. Ogunrinola), okafolabi@lautech.edu.ng (O.K. Afolabi),

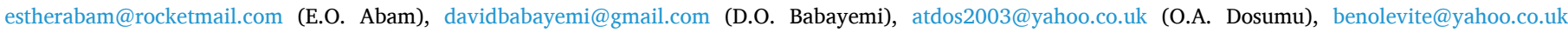
(O.B. Onunkwor), ea_balogun@yahoo.com (E.A. Balogun), ooodukoya@yahoo.com (O.O. Odukoya), adelad2@yahoo.com (O. Ademuyiwa).
} 
forms, each with a specific toxicity profile: Elemental or metallic mercury $\left(\mathrm{Hg}^{0}\right)$, inorganic mercury and organic mercury [5-8]. Elemental $\mathrm{Hg}$ exists as a liquid at room temperature and can be released easily into the atmosphere because of its high vapour pressure. Inorganic $\mathrm{Hg}$ is found in 2 oxidation states: mercurous $\left(\mathrm{Hg}^{+}\right)$and mercuric $\left(\mathrm{Hg}^{++}\right)$. The mercuric state may also form organic compounds such as methyl-, ethyl-, phenylor dimethylmercury [5-8]. The toxicity profiles, biological behaviour, toxicokinetics, toxicodynamics as well as other outcomes of $\mathrm{Hg}$, depend on their chemical forms. While elemental and organic $\mathrm{Hg}$ are lipid-soluble and their toxicity profiles are well represented in the literature, the low liposolubility, low absorption and low passage through the blood-brain-barrier (BBB) of inorganic $\mathrm{Hg}$ have resulted in the paucity of data about the toxic responses associated with exposure to this inorganic form of $\mathrm{Hg}$ [1].

About three decades ago, Nielsen [9], predicted that future human exposure to inorganic $\mathrm{Hg}$ would probably lead to a few individuals occupationally exposed to high levels and much larger populations exposed to low or very low levels from dental fillings or food items containing inorganic Hg. Increased use of inorganic $\mathrm{Hg}$ as drugs, skin lightning creams and germicides has been observed over the years thus resulting in human exposure [5-8]. Non-medical uses of inorganic $\mathrm{Hg}$ include wood preservative, photographic intensifier, dry battery depolariser, tanning agent for leather and catalyst in the manufacture of chemicals such as vinylchloride [10]. In recent times, one anthropogenic activity (artisanal gold mining in which $\mathrm{Hg}$ is used to separate gold from lead), has witnessed a surge in the entry of women and children resulting in chronic exposure of entire households to relatively high levels of inorganic $\mathrm{Hg}[11,12]$.

Exposure to inorganic $\mathrm{Hg}$ is associated with a wide range of toxic end-points including neurological [8], renal [13], hepatic [14], gastro-intestinal [15], reproductive [16], cardiovascular [17] and developmental [18]. Most of these studies used male animals in delineating these toxic end-points. In addition, biomarkers of toxicity used were skewed towards oxidative stress and anti-oxidants. However, epidemiological studies have recognised lipidomics as an independent risk factor in the pathogenesis and progression of an array of pathologies ranging from atherosclerosis, cardiovascular disease to cancer [19]. There is also increasing evidence that environmental factors/contaminants (most especially heavy metals), are at the heart of this dyslipidemia in both humans and animals [20-24]. Our study provides a model to investigate sexual dimorphism in the toxicokinetics and toxicodynamics of orally administered low dose inorganic $\mathrm{Hg}$ in the rat using lipidomics as metrics of toxicodynamics and outcomes. The findings of higher levels of $\mathrm{Hg}$ in the organs of the females as compared to males, as well as different patterns of dyslipidemia in male vs. female and vice versa, provide ample evidence that sexual dimorphism is a common signature of the toxic responses to environmentally relevant low dose inorganic $\mathrm{Hg}$ exposure in the rat.

\section{Materials and methods}

\subsection{Chemicals}

Mercury chloride was purchased from Sigma-Aldrich, Missouri, USA.

\subsection{Animals and treatment}

Experimental protocols were conducted in accord with guidelines of the Institutional Animal Care and Use Committee and were approved by the Animal Ethical Committee of the Department of Biochemistry, Federal University of Agriculture, Abeokuta, Nigeria (FUNAAB/CBS/ BCH/050269).

Sixty four Wistar rats (32 males and 32 females) bred in the College of Veterinary Medicine, Federal University of Agriculture, Abeokuta, Nigeria with body weights between 150 and 250 g (8-10 weeks old), were used for the study. They were housed in an animal room with normal controlled temperature $\left(22 \pm 2{ }^{\circ} \mathrm{C}\right)$ and a regular $12 \mathrm{~h}$ light-dark cycle (06:00-18:00 h). They were allowed 14 days to acclimatise before the commencement of inorganic $\mathrm{Hg}$ exposure. The animals were maintained on a standard pellet diet and had access to water ad libitum.

Animals in each sex group were divided into 4 groups of 8 animals each. While 2 groups served as control and received distilled water, the remaining groups (3 groups in each sex group) were exposed to $\mathrm{Hg}(0.5$, 1.0 and $1.5 \mathrm{mg} \mathrm{Hg} / \mathrm{kg}$ body weight) as mercuric chloride twice a week orally (by gavage) for 12 weeks (Fig. 1). These $\mathrm{Hg}$ doses and frequency were chosen based on previous studies [25-27]. At the end of $\mathrm{Hg}$ exposure, blood was collected from the abdominal arteries of the animals into heparinised tubes under light ether anaesthesia after an overnight fast. Liver, kidney, heart, lung, brain and spleen were also removed from the animals for $\mathrm{Hg}$ and lipid analyses. An aliquot of the blood samples was taken for $\mathrm{Hg}$ determination while the remaining blood samples were centrifuged to separate plasma and red blood cells. All samples were stored at $-20^{\circ} \mathrm{C}$ until analysed.

\subsection{Mercury determination}

A portion of the frozen organs $(\approx 200 \mathrm{mg})$ and whole blood $(0.2 \mathrm{ml})$ were digested in nitric and sulphuric acid mixture $(1: 3, \mathrm{v} / \mathrm{v})$. Total $\mathrm{Hg}$ was determined using Inductively-Coupled Plasma Spectrometry-Mass Spectrometry (ICP-MS) (Agilent 7700, U.S.A).

One blank and one certified reference (NIST Multielement Stock Solution, Inorganic Ventures, Christianburg, VA, USA), as well as samples spiked with known concentrations of the reference material were included in each batch of digestion. Calibration curves were obtained using 6 points with the certified standard. After each analytical run (usually 20 samples), calibration curves were obtained again to check for linearity and replication. A mean recovery rate of $>95 \%$ was obtained for $\mathrm{Hg}$ and other elements after two determinations. Results are expressed as $\mu \mathrm{g} \mathrm{Hg} / \mathrm{ml}$ of blood and $\mu \mathrm{g} \mathrm{Hg} / \mathrm{g}$ wet weight of the organs.

\subsection{Biochemical analyses}

\subsubsection{Plasma and lipoprotein lipid profiles}

Determination of the major lipids (cholesterol, triglycerides, phospholipids and free fatty acids) in plasma and lipoproteins followed established procedures. Details of these have been given in our earlier studies [20-22,28,29].

\subsubsection{Organ and erythrocyte lipid profiles}

Lipids were extracted from the organs (liver, kidney, heart, lung, brain and spleen) as described by Folch et al. [30] while extraction of erythrocyte lipids followed the procedure described by Rose and Oklander [31]. After washing with $0.05 \mathrm{M} \mathrm{KCl}$ solution, aliquots of the lipid extracts were then used for the determination of lipid profiles. Details of these are given as reported earlier [20-22,28,29].

\subsection{Statistical analysis}

Results are expressed as mean \pm SEM. Two way analysis of variance (ANOVA) followed by Tukey's test and pairwise comparisons were used to analyse the results with $\mathrm{p}<0.05$ considered significant.

\section{Results}

$\mathrm{Hg}$ concentrations in the tissues of the animals are shown in Table 1. Irrespective of the sex, no appreciable amount of $\mathrm{Hg}$ was found in the blood of the animals. In contrast to blood, $\mathrm{Hg}$ accumulation in other soft tissues exhibited different patterns characterised by sexual dimorphism and organ specificity. While there was no uptake of $\mathrm{Hg}$ by the brain, a slight but significant uptake of $\mathrm{Hg}$ was observed in the spleen of female animals exposed to $1.0 \mathrm{mg} \mathrm{Hg} / \mathrm{kg}$ body weight. Cardiac $\mathrm{Hg}$ uptake was saturated in both sexes on the exposure of the animals to $0.5 \mathrm{mg} \mathrm{Hg} / \mathrm{kg}$ 


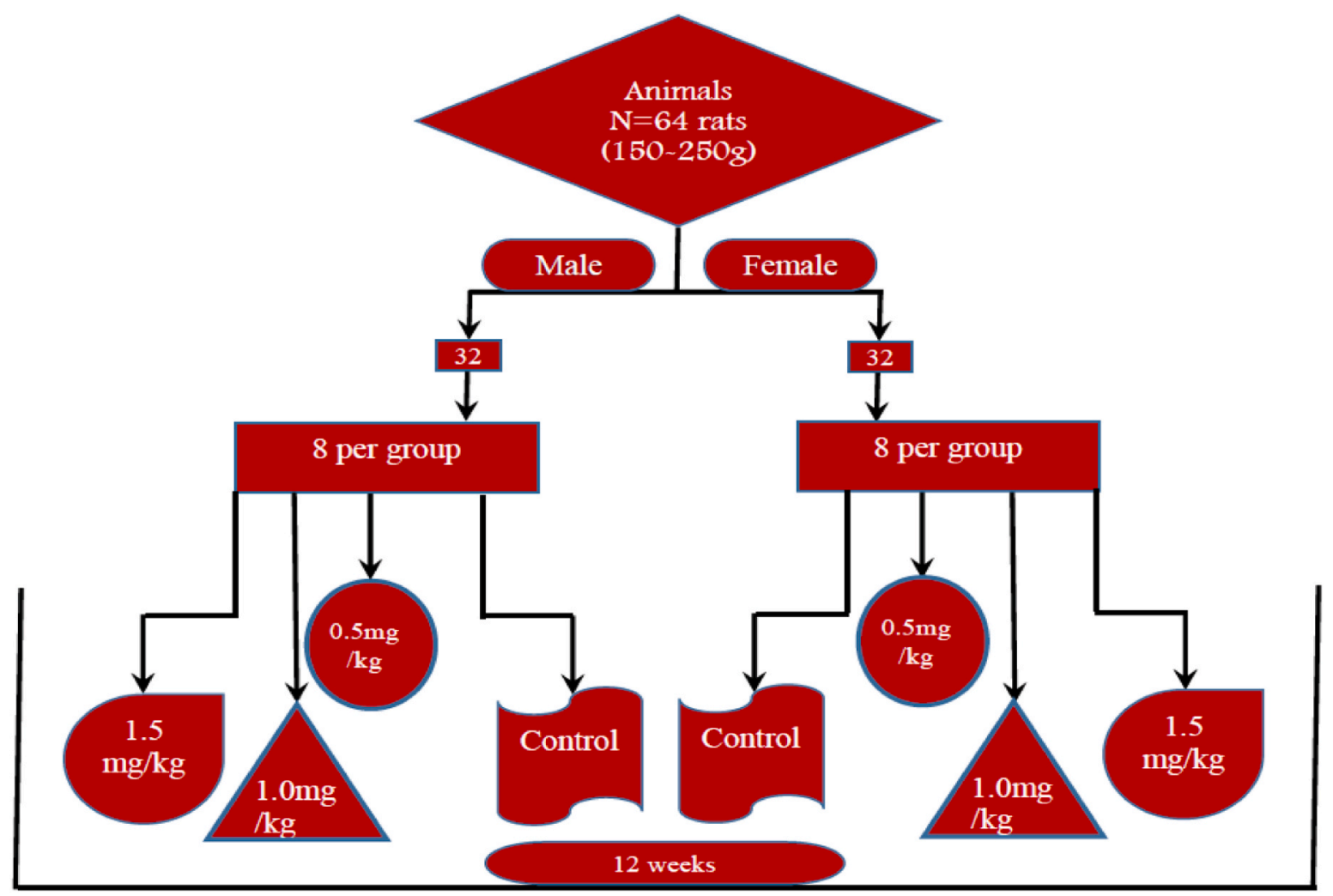

Fig. 1. Experimental protocol and animal treatment.

Table 1

Mercury concentrations in the tissues of the animals.

\begin{tabular}{|c|c|c|c|c|c|c|c|c|}
\hline \multirow[t]{3}{*}{ Compartments } & \multicolumn{8}{|c|}{ Mercury dose (mg/kg body weight) } \\
\hline & \multicolumn{2}{|l|}{ Control } & \multicolumn{2}{|l|}{0.5} & \multicolumn{2}{|l|}{1.0} & \multicolumn{2}{|l|}{1.5} \\
\hline & Male & Female & Male & Female & Male & Female & Male & Female \\
\hline Liver $\mathrm{Hg} \mu \mathrm{g} / \mathrm{g}$ & $0.08 \pm 0.01^{\mathrm{a}}$ & $0.20 \pm 0.03^{\mathrm{b}}$ & $0.05 \pm 0.01^{\mathrm{a}}$ & $0.61 \pm 0.02^{\mathrm{c}}$ & $0.17 \pm 0.01^{\mathrm{b}}$ & $1.37 \pm 0.18^{\mathrm{e}}$ & $0.20 \pm 0.01^{\mathrm{b}}$ & $0.89 \pm 0.06^{\mathrm{d}}$ \\
\hline Kidney $\mathrm{Hg} \mu \mathrm{g} / \mathrm{g}$ & $0.14 \pm 0.01^{\mathrm{a}}$ & $0.32 \pm 0.03^{\mathrm{b}}$ & $29.21 \pm 0.88^{\mathrm{e}}$ & $22.58 \pm 1.75^{\mathrm{d}}$ & $17.47 \pm 0.21^{\mathrm{c}}$ & $43.83 \pm 4.91^{\mathrm{f}}$ & $23.78 \pm 1.59^{\mathrm{d}}$ & $77.89 \pm 7.71^{g}$ \\
\hline Heart $\mathrm{Hg} \mu \mathrm{g} / \mathrm{g}$ & $0.16 \pm 0.04^{\mathrm{a}}$ & $0.20 \pm 0.01^{\mathrm{b}}$ & $0.75 \pm 0.01^{\mathrm{e}}$ & $0.75 \pm 0.01^{\mathrm{e}}$ & $0.75 \pm 0.01^{\mathrm{e}}$ & $0.75 \pm 0.01^{\mathrm{e}}$ & $0.66 \pm 0.03^{\mathrm{d}}$ & $0.42 \pm 0.03^{\mathrm{c}}$ \\
\hline Spleen $\mathrm{Hg} \mu \mathrm{g} / \mathrm{g}$ & $0.08 \pm 0.01^{\mathrm{a}}$ & $0.03 \pm 0.01^{\mathrm{b}}$ & $0.07 \pm 0.01^{\mathrm{a}}$ & $0.08 \pm 0.01^{\mathrm{a}}$ & $0.06 \pm 0.01^{\mathrm{a}}$ & $0.17 \pm 0.01^{\mathrm{d}}$ & $0.09 \pm 0.01^{\mathrm{c}}$ & $0.1 \pm 0.01^{\mathrm{c}}$ \\
\hline
\end{tabular}

Each value represents the mean \pm S.E.M. of 8 rats. Values within a row with different alphabets are significantly different from each other, $\mathrm{p}<0.05$, compared to control male.

body weight. Doubling the $\mathrm{Hg}$ dose did not produce any further uptake of $\mathrm{Hg}$. A tripling of the inorganic $\mathrm{Hg}$ dose, however, resulted in a decrease in cardiac $\mathrm{Hg}$ content (12\% in male and $44 \%$ in female). In spite of this decrease at the highest dose of inorganic $\mathrm{Hg}$, cardiac $\mathrm{Hg}$ contents were still 4 and 2 times higher than that of male and female controls respectively. Pulmonary $\mathrm{Hg}$ uptake peaked at $4.33 \pm 1.77 \mu \mathrm{g} / \mathrm{g}$ tissue in male animals exposed to $0.5 \mathrm{mg} \mathrm{Hg} / \mathrm{kg}$ body weight followed by a $94 \%$ decrease at the highest dose of inorganic Hg. The female animals, on the other hand had their pulmonary $\mathrm{Hg}$ increased from $0.10 \pm 0.01 \mu \mathrm{g} / \mathrm{g}$ to $0.83 \pm 0.17 \mu \mathrm{g} / \mathrm{g}$ tissue in a dose-dependent manner. Hepatic $\mathrm{Hg}$ uptake was also characterised by sexual dimorphism, with female picking up more $\mathrm{Hg}$ than their male counterparts.

In contrast to other organs, the kidney bioaccumulated more $\mathrm{Hg}$ and at a faster rate in both sexes. While the renal accumulation of $\mathrm{Hg}$ in male animals was not dose-dependent, a dose-dependent accumulation of $\mathrm{Hg}$ was observed in the kidney of the female animals. At the highest dose of inorganic $\mathrm{Hg}$, the female accumulated 3.3 times more $\mathrm{Hg}$ than their male counterparts. Pairwise comparison reveal that female organs tended to take up more $\mathrm{Hg}$ than the males and the uptake appears to be dosedependent.

Plasma lipid profiles of the animals are depicted in Fig. 2. Hginduced dyslipidemia was characterised by hypercholesterolemia in the male animals at all the doses while hypocholesterolemia (49\%) was observed in the female with $1.0 \mathrm{mg} \mathrm{Hg} / \mathrm{kg}$ body weight (Fig. 2A). Hypertriglyceridemia (Fig. 2B) in both sexes was the hallmark of inorganic $\mathrm{Hg}$ exposure. Comparatively, this was more prevalent at lower doses of inorganic $\mathrm{Hg}$ in the male than the female. In contrast to cholesterol and triglycerides, inorganic $\mathrm{Hg}$ exposure did not have any effect on plasma phospholipids of the female animals whereas, at the highest dose of inorganic $\mathrm{Hg}$, plasma phospholipids of the male animals was twice that of their female counterparts (Fig. 2C).

The response of reverse lipid transport in the animals to the presence of inorganic $\mathrm{Hg}$ is depicted in Fig. 3. In male animals, there was a gradual decrease in HDL cholesterol and phospholipids, even though the decrease was not dose-dependent (Fig. 3A and C). Although HDL cholesterol and phospholipids also decreased in the female animals, the 
Cholesterol (A)

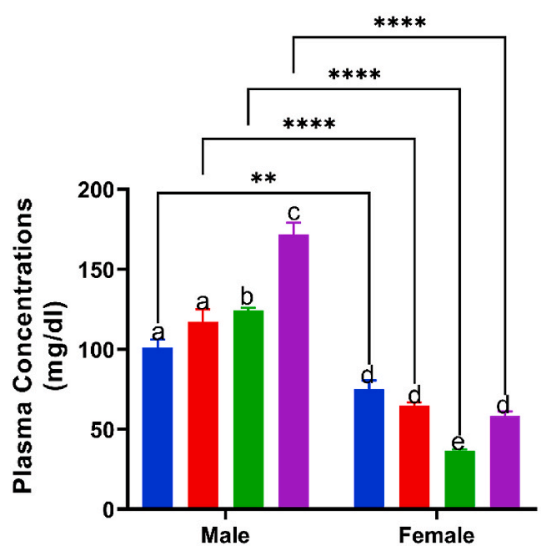

Triglycerides (B)

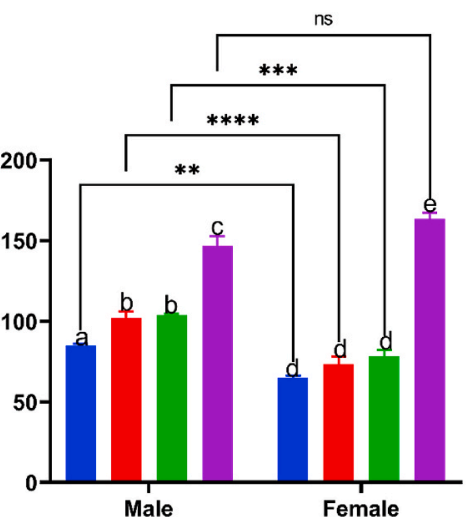

Phospholipid (C)

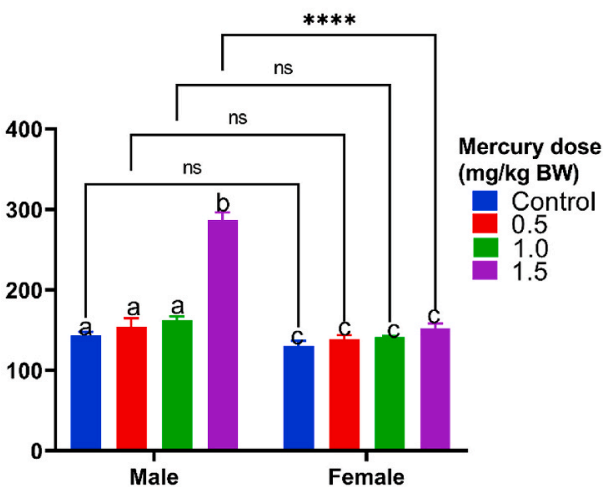

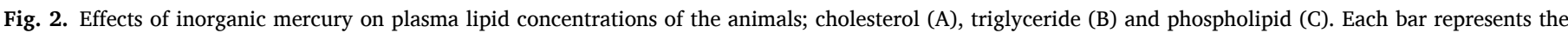
mean \pm SEM of 8 rats. Bars with different alphabets are significantly different from each other at $\mathrm{p}<0.05$ compared to their control counterpart.
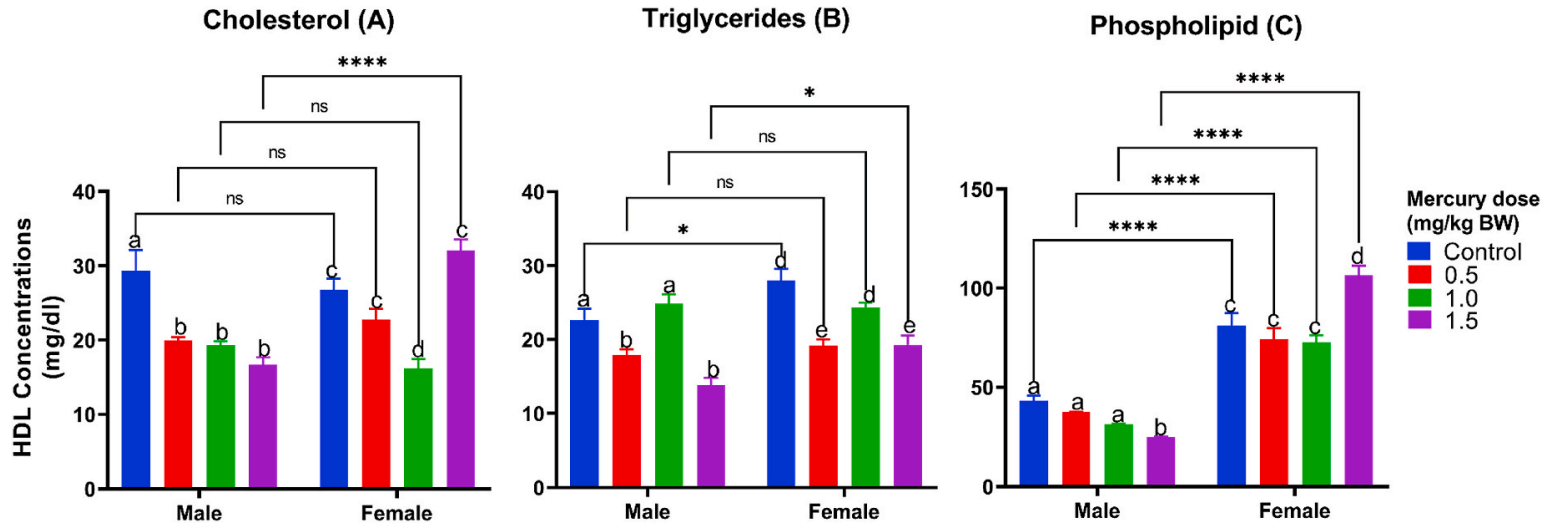

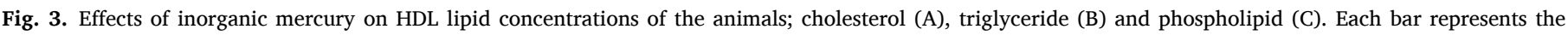
mean \pm SEM of 8 rats. Bars with different alphabets are significantly different from each other at $\mathrm{p}<0.05$ compared to their control counterpart.

highest dose of inorganic $\mathrm{Hg}$ resulted in an increase in the two lipids in this lipoprotein. In both control and inorganic Hg-exposed animals, HDL phospholipids was twice as much in female animals than their male counterparts (Fig. 3C). In contrast to cholesterol and phospholipids, inorganic Hg-induced changes in HDL triglycerides exhibited a sinusoidal pattern-a decrease, followed by an increase and a further decrease (Fig. 3B).
VLDL lipid profile is depicted in Fig. 4. While exposure to the $0.5 \mathrm{mg}$ $\mathrm{Hg} / \mathrm{kg}$ body weight did not seem to have any effect on VLDL cholesterol in both sexes (Fig. 4A), the remaining two doses of inorganic $\mathrm{Hg}$ (1.0 and $1.5 \mathrm{mg} \mathrm{Hg} / \mathrm{kg}$ body weight) seem to modulate VLDL cholesterol in both sexes differently. While the $1.0 \mathrm{mg} \mathrm{Hg} / \mathrm{kg}$ body weight increased male VLDL cholesterol by $28 \%$, female VLDL cholesterol was decreased by $52 \%$. Increasing the inorganic $\mathrm{Hg}$ dose to $1.5 \mathrm{mg} \mathrm{Hg} / \mathrm{kg}$ body weight
Cholesterol (A)

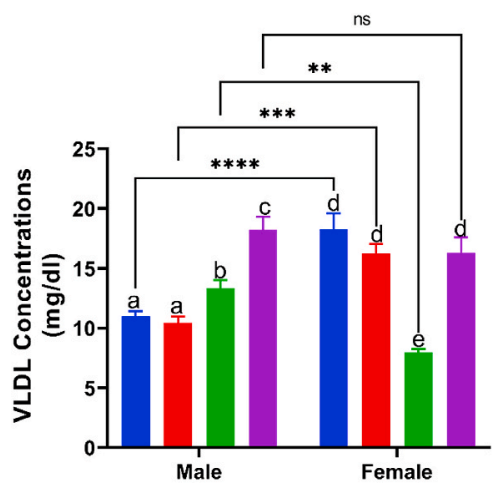

Triglycerides (B)

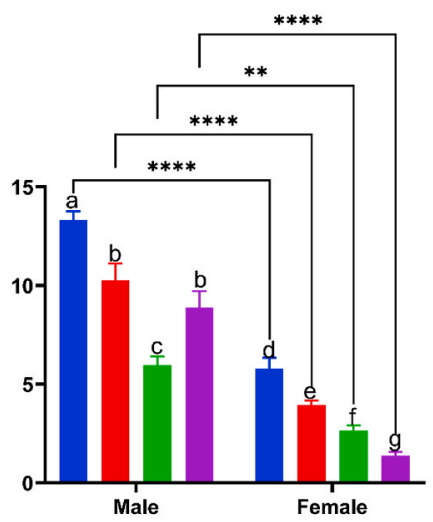

Phospholipid (C)

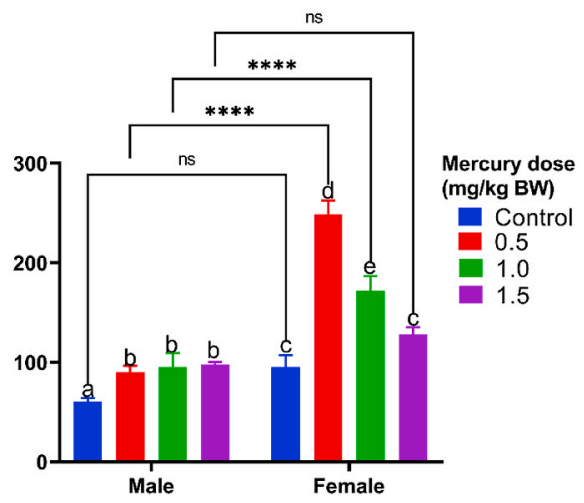

Fig. 4. Effects of inorganic mercury on VLDL lipid concentrations of the animals; cholesterol (A), triglyceride (B) and phospholipid (C). Each bar represents the mean \pm SEM of 8 rats. Bars with different alphabets are significantly different from each other at $p<0.05$ compared to their control counterpart. 
resulted in further increase in male VLDL cholesterol whereas the increase observed in female VLDL cholesterol brought their cholesterol back to control level. In contrast to VLDL cholesterol, exposure to all the inorganic $\mathrm{Hg}$ doses resulted in a depletion of VLDL triglyceride in both sexes (Fig. 4B). The depletion was gradual and continuous/dosedependent in the female whereas there was a rebound to higher VLDL triglyceride in the male animals; although at the highest $\mathrm{Hg}$ dose, male VLDL triglyceride was just $67 \%$ of control while female VLDL triglyceride was $24 \%$ of their control female counterparts. With exposure to the $0.5 \mathrm{mg} \mathrm{Hg} / \mathrm{kg}$ body weight, female VLDL phospholipid attained a peak of about $250 \mathrm{mg}$ phospholipid (Fig. 4C). Doubling the inorganic $\mathrm{Hg}$ dose resulted in a depletion of about $100 \mathrm{mg}$ phospholipid. Tripling the inorganic $\mathrm{Hg}$ dose resulted in a further depletion of this lipoprotein's phospholipid by another $40 \mathrm{mg}$. In contrast however, male VLDL phospholipid increased from $58.02 \pm 4.56$ to $85.05 \pm 8.90 \mathrm{mg} / \mathrm{dL}$ on exposure to $0.5 \mathrm{mg} \mathrm{Hg} / \mathrm{kg}$ body weight. Doubling and tripling the inorganic $\mathrm{Hg}$ doses did not result in any appreciable increase as the male VLDL phospholipid content peaked at about $100 \mathrm{mg}$.

Erythrocyte lipids of the animals are shown in Fig. 5. There was a significant increase in all the three lipids in the erythrocytes of female animals. Although the increase was not dose-dependent, the highest increase in each lipid was observed in female animals exposed to the highest dose of inorganic $\mathrm{Hg}$. While a 2-fold increase was observed in cholesterol (Fig. 5A), a 3-fold increase was observed in phospholipids (Fig. 5C). A $41 \%$ increase was however observed in erythrocyte triglycerides (Fig. 5B). In contrast to female animals, the three doses of inorganic $\mathrm{Hg}$ only up-regulated erythrocyte triglycerides in male animals in a non-dose-dependent manner (Fig. 5B). Furthermore, the $1.0 \mathrm{mgHg} / \mathrm{kg}$ body weight of inorganic $\mathrm{Hg}$ in the male animals decreased erythrocyte cholesterol by $46 \%$ while the $1.5 \mathrm{mgHg} / \mathrm{kg}$ body weight dose of inorganic $\mathrm{Hg}$ decreased erythrocyte phospholipids by about $33 \%$.

Erythrocyte membrane (EM) lipid profiles as a result of exposure to inorganic $\mathrm{Hg}$ are shown in Fig. 6. Cholesterol was depleted 77, 50 and $73 \%$ respectively in EM of male animals whereas the decrease amounted to $73 \%$ in female animals on exposure to the highest dose of inorganic $\mathrm{Hg}$ (Fig. 6A). As indicated in Fig. 6B, EM triglyceride was depleted in both sexes by exposure to inorganic Hg. EM phospholipid (Fig. 6C) in both sexes responded with a decrease on exposure to inorganic $\mathrm{Hg}$. Comparatively, the decrease was more pronounced in the female animals than their male counterparts.

Fig. 7 depicts plasma and erythrocyte free fatty acids (FFA) in the animals. In both compartments, exposure to inorganic $\mathrm{Hg}$ resulted in a steady increase in FFA in both male and female animals. In addition, in both control and $\mathrm{Hg}$-exposed animals, plasma FFA in female animals was about two times that of their male counterparts (Fig. 7A) whereas the response of erythrocyte FFA in male animals exposed to inorganic $\mathrm{Hg}$ was about $30 \%$ more than that of their female counterparts (Fig. 7B).
Cholesterol concentrations in brain, liver, kidney, heart, lung and spleen are depicted in Fig. 8. Inorganic $\mathrm{Hg}$ exposure resulted in the depletion of brain cholesterol in both sexes, except with the $0.5 \mathrm{mg} / \mathrm{kg}$ body weight of $\mathrm{Hg}$ where a slight but significant increase in brain cholesterol was observed (Fig. 8A). While a non-dose-dependent hepatic and pulmonary cholesterogenesis was observed in the male animals (Fig. 8B and E), inorganic Hg exposure did not affect female hepatic and pulmonary cholesterol (Fig. $8 \mathrm{~B}$ and E). Renal cholesterol was not affected in the male animals (Fig. 8C) (p >0.05), whereas the lowest and highest doses of inorganic $\mathrm{Hg}$ depleted female renal cholesterol by about $30 \%$ (Fig. 8C). At the highest dose of inorganic $\mathrm{Hg}$, there was a $67 \%$ depletion of cardiac cholesterol in male animals whereas the same dose of inorganic $\mathrm{Hg}$ induced cardiac cholesterogenesis in the females (Fig. 8D). A 50\% depletion in splenic cholesterol was observed in male $(1.0 \mathrm{mg} / \mathrm{kg}$ body weight of $\mathrm{Hg}$ ) and female $(1.5 \mathrm{mg} / \mathrm{kg}$ body weight of $\mathrm{Hg}$ ) animals respectively (Fig. 8F).

As depicted in Fig. 9A, only the highest dose of inorganic $\mathrm{Hg}$ resulted in an appreciable increase in brain triglyceride content in both sexes. While the increase amounted to $125 \%$ in male animals, there was a $75 \%$ increase in the female. Hepatic triglyceride increased in male animals exposed to 1.0 and $1.5 \mathrm{mg} / \mathrm{kg}$ body weight of inorganic $\mathrm{Hg}$ whereas only the highest dose of inorganic $\mathrm{Hg}$ increased hepatic triglyceride in female animals (Fig. 9B). On exposure of the animals to $0.5 \mathrm{mg} / \mathrm{kg}$ body weight of inorganic $\mathrm{Hg}$, renal triglyceride decreased by $50 \%$ in both sexes (Fig. 9C). Doubling the $\mathrm{Hg}$ dose brought back renal triglyceride to control values in the female while a 2 -fold increase was observed in the male animals. With a further increase in $\mathrm{Hg}$ dose, renal triglyceride in both sexes was not significantly different from controls ( $p>0.05)$. Inorganic $\mathrm{Hg}$ exposure did not affect cardiac triglyceride in female animals ( $>$ > 0.05) (Fig. 9D). In contrast however, the $0.5 \mathrm{mg} / \mathrm{kg}$ body weight of inorganic $\mathrm{Hg}$ increased cardiac triglyceride by $25 \%$ in the male animals while the $1.5 \mathrm{mg} / \mathrm{kg}$ body weight of inorganic $\mathrm{Hg}$ decreased cardiac triglyceride by $25 \%$. Irrespective of the dose, pulmonary triglyceride was not affected in the male by $\mathrm{Hg}$ exposure whereas a 6 -fold increase in pulmonary triglyceride was observed in the female animals exposed to the highest dose of inorganic $\mathrm{Hg}$ (Fig. 9E).

As indicated in Fig. 9F, exposure to $1.0 \mathrm{mg} / \mathrm{kg}$ body weight of inorganic $\mathrm{Hg}$ resulted in depletion of splenic triglyceride (54\% in the male and $41 \%$ in the female). Increasing the $\mathrm{Hg}$ dose restored splenic triglyceride to control values in the female whereas splenic triglyceride in the male attained $67 \%$ of control value.

Depletion of brain and cardiac phospholipids was the hallmark of inorganic $\mathrm{Hg}$ exposure in the animals irrespective of the sex. (Fig. 10A and D). Comparatively, the depletion was more pronounced in the female animals compared to their male counterparts. In contrast to both brain and heart, phospholipidosis characterised inorganic $\mathrm{Hg}$ effect in both sexes in the liver (Fig. 10B) whereas pulmonary phospholipidosis
Cholesterol (A)

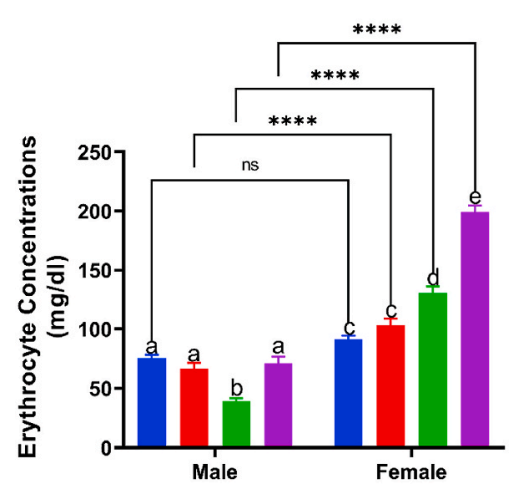

Triglycerides (B)

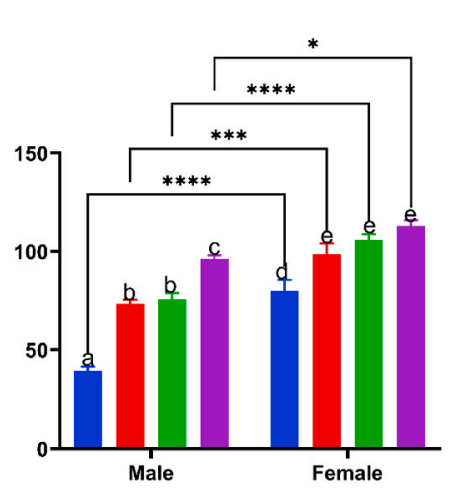

Phospholipids (C)

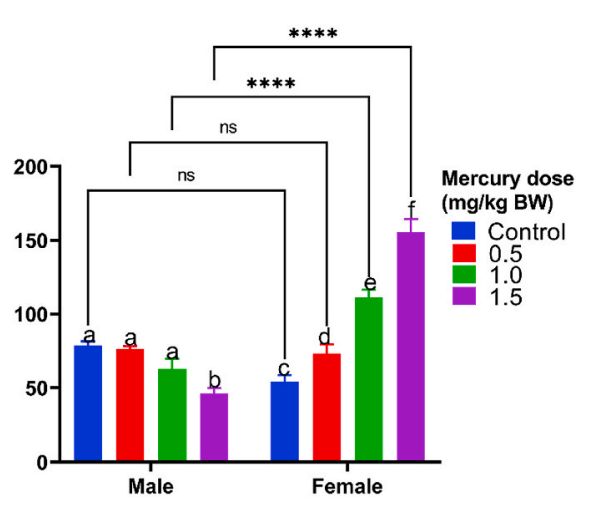

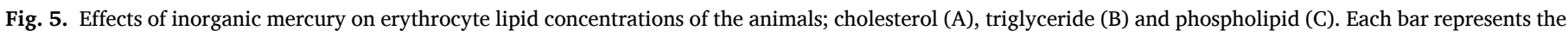
mean \pm SEM of 8 rats. Bars with different alphabets are significantly different from each other at $\mathrm{p}<0.05$ compared to their control counterpart. 
Cholesterol (A)

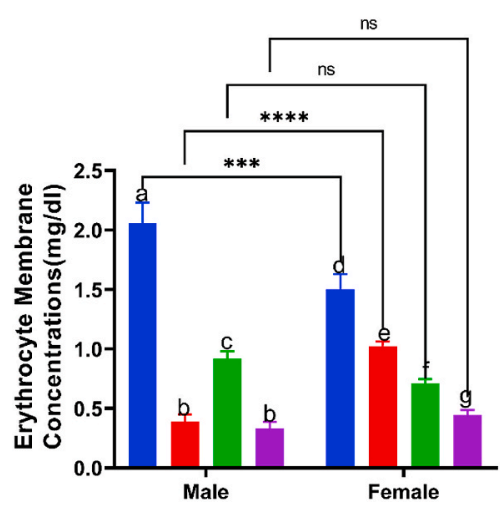

Triglycerides (B)

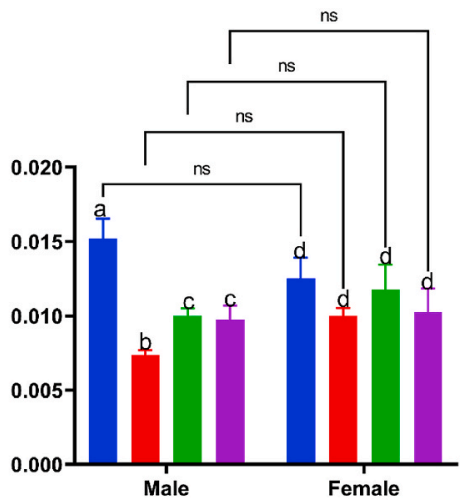

Phospholipid (C)

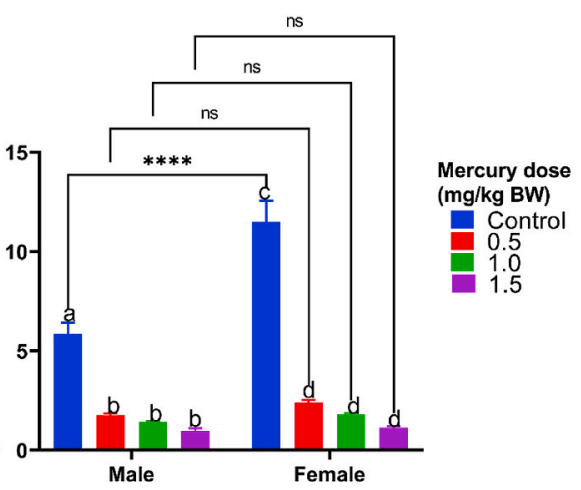

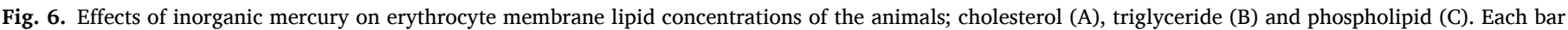

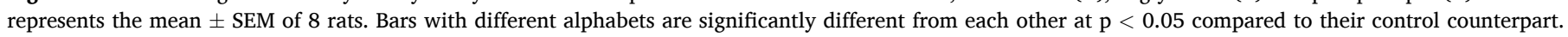

Plasma (A)

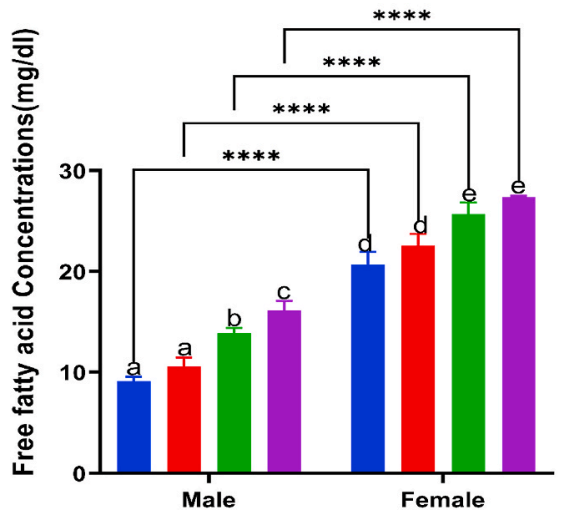

Red Blood Cell (B)

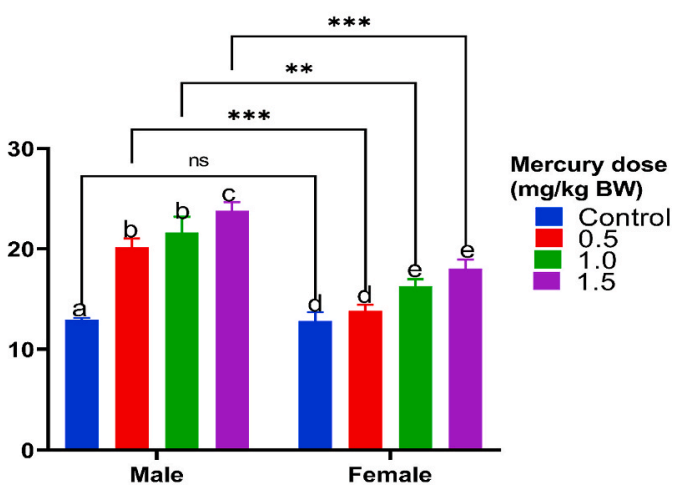

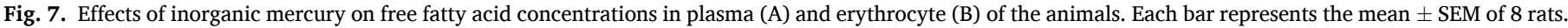
Bars with different alphabets are significantly different from each other at $\mathrm{p}<0.05$ compared to their control counterpart.

was only observed in male animals (Fig. 10E). Inorganic Hg exposure did not affect renal phospholipids in both sexes (p > 0.05) (Fig. 10C). A transient, but significant phospholipidosis was observed in the spleen of female animals on exposure to the $0.5 \mathrm{mg} / \mathrm{kg}$ body weight dose of $\mathrm{Hg}$ (Fig. 10F). Doubling and tripling the $\mathrm{Hg}$ doses however resulted in depletion of splenic phospholipids in both sexes.

Cholesterol:phospholipid ratios in different compartments of the animals on exposure to inorganic $\mathrm{Hg}$ are indicated in Table 2. Three distinct patterns could be recognised. In the first pattern, this ratio decreased in male animals but increased in their female counterparts. This pattern was found in the cardiac and pulmonary compartments. In the second pattern, the ratio increased in males, but decreased in the females as exemplified by renal and hepatic compartments. Erythrocyte and plasma cholesterol:phospholipid ratios were epitomes of the third pattern in which the ratio both decreased and increased in the males, but decreased in the females. In the EM however, cholesterol:phospholipid ratio both decreased and increased in the male while increasing in the female.

\section{Discussion}

The findings of this study indicate that sexual dimorphism not only characterised the toxicokinetics of sub-chronic inorganic $\mathrm{Hg}$ exposure in the rat, the attendant toxicodynamics as reflected by lipotoxic and nonlipotoxic dyslipidemia, was also sexually dimorphic. While only one pattern of sexual dimorphism could be recognised in $\mathrm{Hg}$ toxicokinetics, sexual dimorphism in $\mathrm{Hg}$ toxicodynamics (dyslipidemia) exhibited different patterns.

The deposition of a larger fraction of the entire body burden of $\mathrm{Hg}$ in the kidney followed by a smaller fraction in the lungs, heart, and liver as observed in this study, epitomises the "normal" pattern of toxicokinetics of inorganic $\mathrm{Hg}$ exposure reported in the literature [7,9,10,32,33]. However, the attainment of a higher concentration of $\mathrm{Hg}$ in the kidney (and to a smaller extent in the lungs, liver and spleen) of female animals compared to males, was the hallmark of sexual dimorphism in $\mathrm{Hg}$ toxicokinetics observed in this study. This observation was first reported by Friberg [34] following chronic subcutaneous administration of $\mathrm{HgCl}_{2}$ to rats. Female rats not only accumulated more $\mathrm{Hg}$ in their kidney than their male counterparts, the rate of renal clearance was also slower in females than males [34]. This observation of Friberg lost traction as a result of Minamata epidemic ( $\mathrm{Hg}$ poisoning as a result of exposure to methyl Hg) which broke out the same year in Japan. Since then, scientific efforts were concentrated on this organic form of $\mathrm{Hg}$ culminating in a lacuna in information regarding inorganic $\mathrm{Hg}$. However, in related studies a few years later using methyl $\mathrm{Hg}$, similar observations were also made [33,35-37]. In another study using inorganic Hg and F344 rats, a similar magnitude of sexual dimorphism in $\mathrm{Hg}$ toxicokinetics was observed [25]. These then indicate that irrespective of the Hg species administered, sexual dimorphism seems to be a common signature of $\mathrm{Hg}$ toxicokinetics. At lower doses of methyl $\mathrm{Hg}$ in these studies, the female-to-male ratios of $\mathrm{Hg}$ concentrations were less than 1 whereas at higher doses, the ratio exceeded 1 . Data in Table 1 in this study indicate 

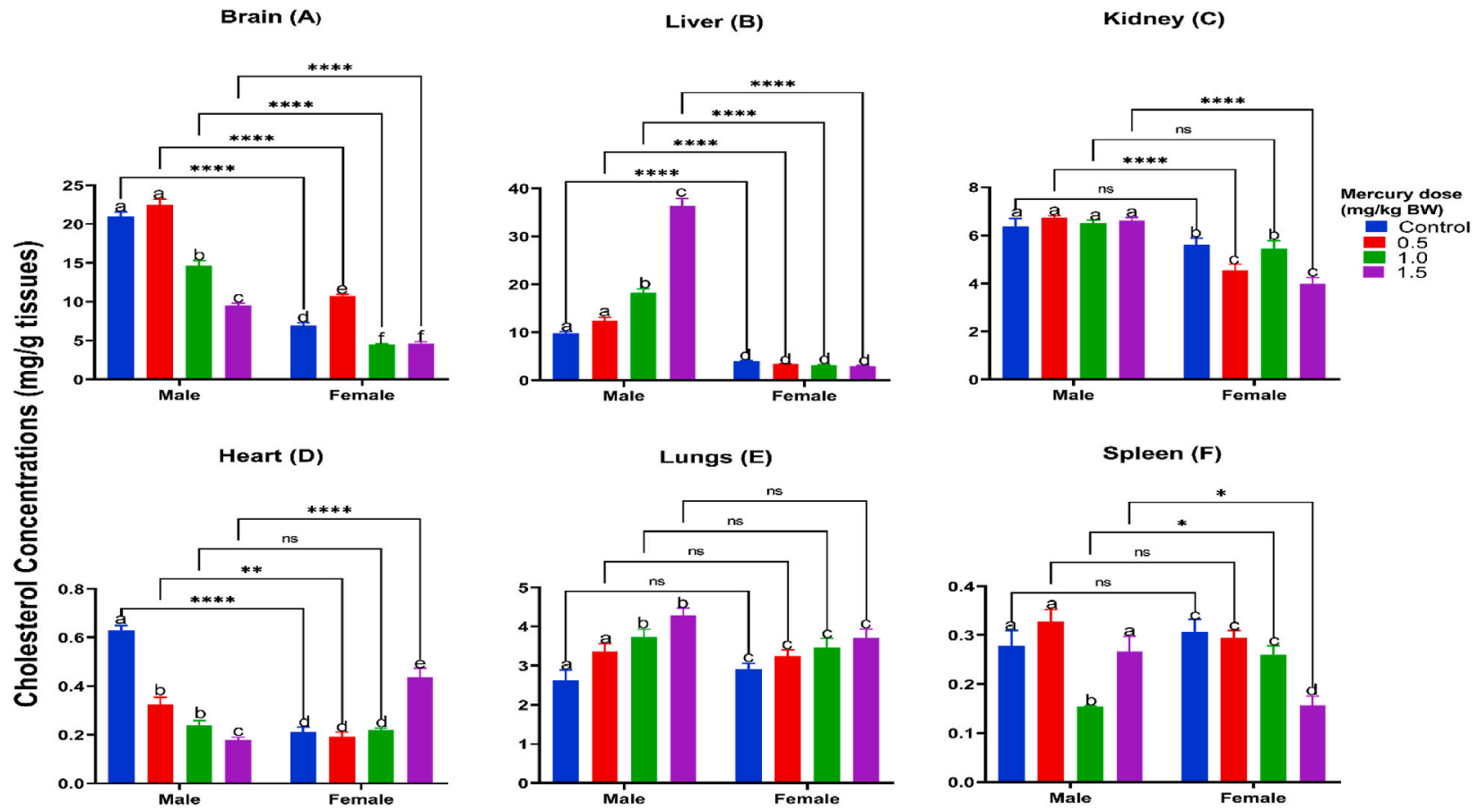

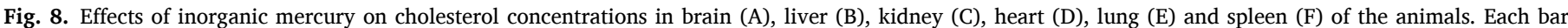

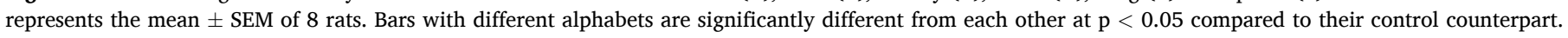

Brain (A)
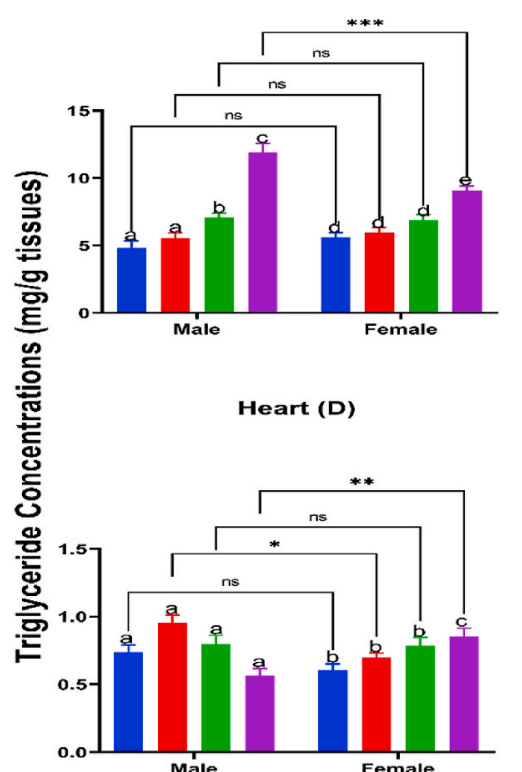

Liver (B)
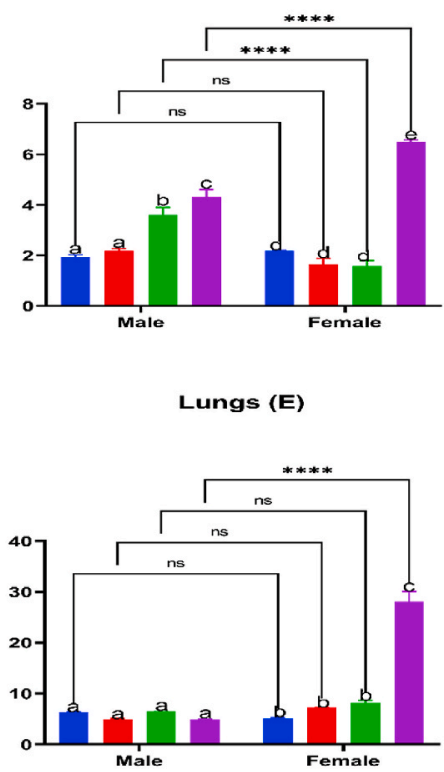

Kidney (C)
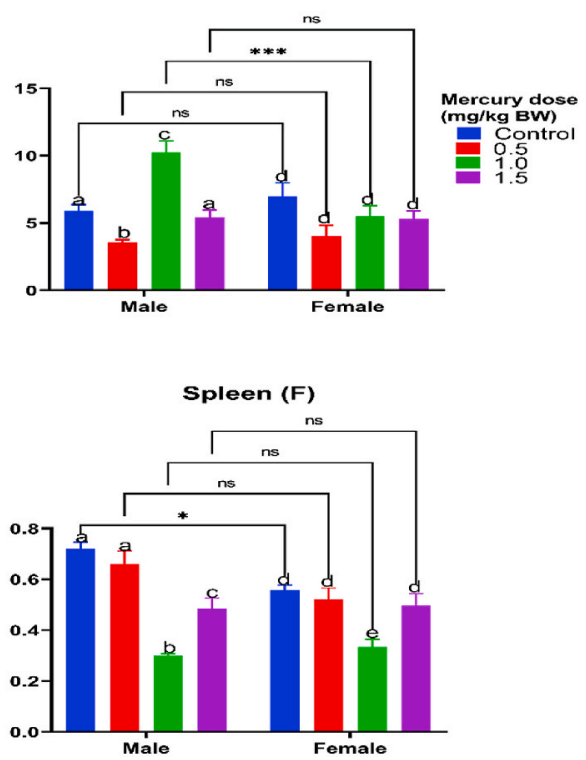

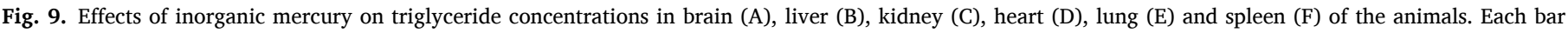

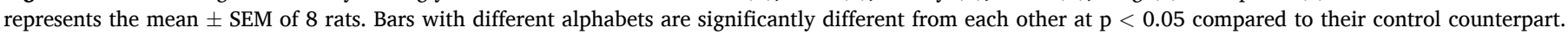

that the ranges of female-to-male ratios of this $\mathrm{Hg}$ accumulation varied from organ to organ. While this ratio was less than 1 for the kidney and lungs on exposure of the animals to $0.5 \mathrm{mg} \mathrm{Hg} / \mathrm{kg}$ body weight, it ranged from 2.5 to 3.3 (kidney), 4.5 to 12.2 (liver), 2.4 to 3.0 (lungs) and 1.1 to 2.8 (spleen) when the rats were exposed to 1.0 and $1.5 \mathrm{mg} \mathrm{Hg} / \mathrm{kg}$ body weight respectively. Although these observations are consistent with what obtains for methyl $\mathrm{Hg}$ and are indicative of slower rate of clearance of $\mathrm{Hg}$ from these organs, it remains to be elucidated whether the uptake mechanism was saturable or not. Results of studies in Ref. [25] using
F344 rats however suggest that after 6 months of inorganic Hg exposure, $\mathrm{Hg}$ did not seem to increase appreciably over time.

The rather high retention of $\mathrm{Hg}$ in the kidney (and probably other organs), has been attributed to the presence of metallothionein, a low molecular weight protein induced in the kidney following exposure to organic and inorganic $\mathrm{Hg}[7,38]$. This protein acts as a sink for $\mathrm{Hg}$ and its binding to the metal has been postulated to protect the kidney against the toxicity of $\mathrm{Hg}[7,38]$. The involvement of an estrogen-dependent mechanism has also been postulated [39]. 

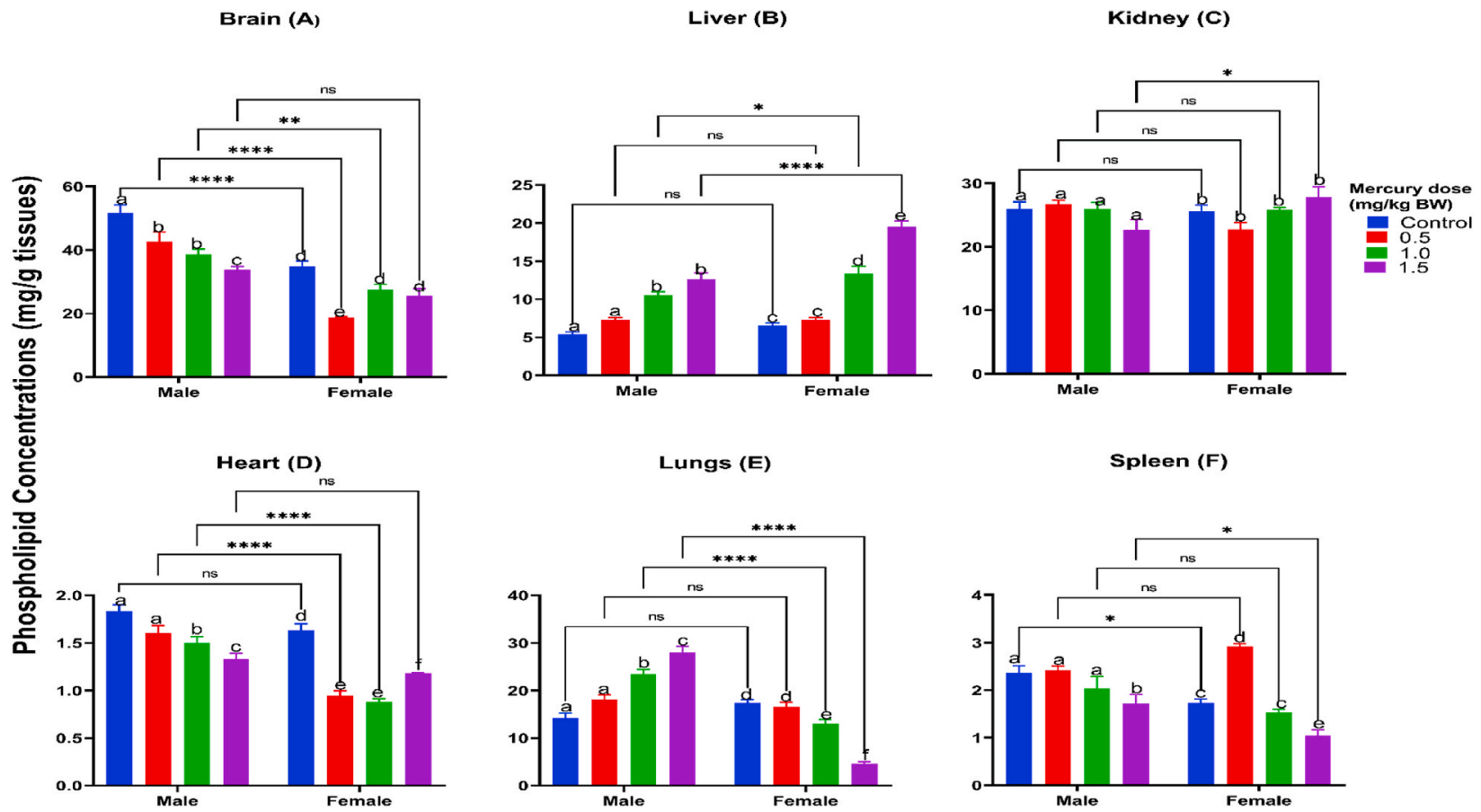

Fig. 10. Effects of inorganic mercury on phospholipid concentrations in brain (A), liver (B), kidney (C), heart (D), lung (E) and spleen (F). Each bar represents the mean \pm S.E.M. of 8 rats. Bars with different alphabets are significantly different from each other at $\mathrm{p}<0.05$ compared to their control counterpart.

Table 2

Cholesterol phospholipid ratios in different compartments of the animals on exposure to inorganic Hg.

\begin{tabular}{|c|c|c|c|c|c|c|c|c|}
\hline \multirow[t]{3}{*}{ Compartments } & \multicolumn{8}{|c|}{ Mercury dose (mg/kg body weight) } \\
\hline & \multicolumn{2}{|l|}{ Control } & \multicolumn{2}{|l|}{$0.5 \mathrm{mg} / \mathrm{kg}$} & \multicolumn{2}{|l|}{$1.0 \mathrm{mg} / \mathrm{kg}$} & \multicolumn{2}{|l|}{$1.5 \mathrm{mg} / \mathrm{kg}$} \\
\hline & Male & Female & Male & Female & Male & Female & Male & Female \\
\hline Plasma & $0.71 \pm 0.03^{\mathrm{a}}$ & $0.58 \pm 0.04^{\mathrm{a}}$ & $0.77 \pm 0.08^{\mathrm{a}}$ & $0.47 \pm 0.02^{b}$ & $0.8 \pm 0.04^{\mathrm{a}}$ & $0.26 \pm 0.01^{\mathrm{c}}$ & $0.63 \pm 0.02^{\mathrm{a}}$ & $0.34 \pm 0.03^{b}$ \\
\hline Erythrocyte & $0.97 \pm 0.05^{\mathrm{a}}$ & $1.80 \pm 0.21^{\mathrm{b}}$ & $0.88 \pm 0.06^{\mathrm{a}}$ & $1.49 \pm 0.16^{\mathrm{b}}$ & $0.68 \pm 0.10^{\mathrm{a}}$ & $1.19 \pm 0.08^{c}$ & $1.59 \pm 0.15^{\mathrm{b}}$ & $1.32 \pm 0.08^{c}$ \\
\hline HDL & $0.70 \pm 0.08^{\mathrm{a}}$ & $0.34 \pm 0.04^{\mathrm{b}}$ & $0.54 \pm 0.01^{\mathrm{a}}$ & $0.32 \pm 0.03^{\mathrm{b}}$ & $0.61 \pm 0.02^{\mathrm{a}}$ & $0.22 \pm 0.01^{\mathrm{b}}$ & $0.68 \pm 0.04^{\mathrm{a}}$ & $0.31 \pm 0.03^{\mathrm{b}}$ \\
\hline Brain & $0.41 \pm 0.03^{\mathrm{a}}$ & $0.20 \pm 0.02^{\mathrm{b}}$ & $0.55 \pm 0.05^{c}$ & $0.57 \pm 0.02^{\mathrm{c}}$ & $0.38 \pm 0.03^{\mathrm{a}}$ & $0.16 \pm 0.01^{b}$ & $0.28 \pm 0.02^{\mathrm{d}}$ & $0.18 \pm 0.01^{b}$ \\
\hline Liver & $1.81 \pm 0.07^{\mathrm{a}}$ & $0.60 \pm 0.05^{\mathrm{b}}$ & $1.74 \pm 0.11^{\mathrm{a}}$ & $0.46 \pm 0.03^{\mathrm{b}}$ & $1.77 \pm 0.14^{\mathrm{a}}$ & $0.25 \pm 0.02^{b}$ & $2.98 \pm 0.27^{c}$ & $0.16 \pm 0.01^{\mathrm{d}}$ \\
\hline Kidney & $0.25 \pm 0.01^{\mathrm{a}}$ & $0.22 \pm 0.02^{\mathrm{a}}$ & $0.24 \pm 0.01^{\mathrm{a}}$ & $0.20 \pm 0.02^{\mathrm{a}}$ & $0.26 \pm 0.01^{\mathrm{a}}$ & $0.21 \pm 0.01^{\mathrm{a}}$ & $0.30 \pm 0.03^{b}$ & $0.14 \pm 0.09^{c}$ \\
\hline Lung & $0.20 \pm 0.03^{\mathrm{a}}$ & $0.17 \pm 0.01^{\mathrm{a}}$ & $0.19 \pm 0.01^{\mathrm{a}}$ & $0.20 \pm 0.02^{\mathrm{a}}$ & $0.16 \pm 0.01^{\mathrm{a}}$ & $0.25 \pm 0.02^{\mathrm{a}}$ & $0.16 \pm 0.00^{\mathrm{a}}$ & $0.88 \pm 0.13^{b}$ \\
\hline Spleen & $0.12 \pm 0.01^{\mathrm{a}}$ & $0.18 \pm 0.02^{\mathrm{b}}$ & $0.13 \pm 0.01^{\mathrm{a}}$ & $0.10 \pm 0.01^{\mathrm{a}}$ & $0.09 \pm 0.02^{\mathrm{a}}$ & $0.17 \pm 0.02^{b}$ & $0.16 \pm 0.02^{\mathrm{b}}$ & $0.16 \pm 0.02^{\mathrm{b}}$ \\
\hline Heart & $0.37 \pm 0.03^{\mathrm{a}}$ & $0.13 \pm 0.01^{b}$ & $0.20 \pm 0.02^{\mathrm{b}}$ & $0.21 \pm 0.02^{\mathrm{b}}$ & $0.17 \pm 0.02^{\mathrm{b}}$ & $0.25 \pm 0.01^{b}$ & $0.14 \pm 0.01^{b}$ & $0.38 \pm 0.01^{\mathrm{a}}$ \\
\hline
\end{tabular}

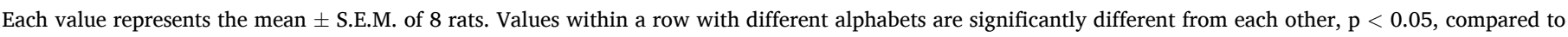
control male.

In contrast to other organs, the brain did not accumulate $\mathrm{Hg}$ to any appreciable extent. This is consistent with reports of previous studies in rats and other animals $[8,40]$ indicating that penetration of the lipid architecture of the BBB by the ionic $\mathrm{Hg}$ is minimal; although it has been suggested that with a prolonged chronic exposure, accompanied by a slow enough elimination, a small percentage of the inorganic $\mathrm{Hg}$ form could be reduced back to the elemental form thereby allowing passage into the brain with subsequent toxicity $[5,8,10,40]$.

Another major finding of this study was that sub-chronic exposure to low doses of inorganic $\mathrm{Hg}$ was associated with lipotoxic and nonlipotoxic perturbations in (an already established sex-linked) lipid homeostasis and that these toxic responses differ between males and females. Although this sexual dimorphism appears mixed, two broad classes could be identified: circulating-lipid and organ-lipid sexual dimorphisms. The composites of circulating-lipid sexual dimorphism include:

1. Hypercholesterolemia in the male as compared to hypocholesterolemia in the female
2. Increased plasma phospholipid in male at the highest dose of inorganic Hg (lipototoxicity) as compared to no effect in female animals.

3. Depletion of erythrocyte cholesterol and phospholipid in male (nonlipotoxicity) as compared to enrichment of these lipids in the erythrocyte of female animals (lipotoxicity)

4. Increase in VLDL cholesterol in male animals (lipotoxicity) as compared to decrease observed in female animals (non-lipotoxicity).

Six composites of organ-lipid sexual dimorphism were identified:

1. Cardiac cholesterogenesis in females (lipotoxicity) at the highest dose of inorganic $\mathrm{Hg}$ as opposed to depletion of cardiac cholesterol in males (non-lipotoxicity).

2. Hepatic cholesterogenesis in males (lipotoxicity) as opposed to no effect in females.

3. Pulmonary cholesterogenesis in males (lipotoxicity) as compared to no effect in females

4. Depletion of renal cholesterol in females (non-lipotoxicity) as opposed to no effect in males 
5. Pulmonary triglyceride constipation in females (lipotoxicity) as opposed to no effect in males

6. Pulmonary phospholipidosis in male (lipotoxicity) as compared to depletion in females (non-lipotoxicity).

Comorbidly in both sexes, plasma and erythrocyte FFA, hepatic and VLDL phospholipid, brain and erythrocyte triglyceride all increased (lipotoxicity), whereas EM phospholipid and triglyceride, brain and hepatic phospholipid as well as VLDL triglyceride decreased (non-lipotoxicity). Even in these comorbidities, sexual dimorphism was still observed as the concentrations of some lipids in the organ lipid pools were higher in one sex than the other. Although the kinetic mechanisms underlying this sexual dimorphism are not understood, several considerations could be made concerning these observations.

Utilisation of major fuel nutrients such as carbohydrate and lipid to meet both structural and energy requirements, constitutes the foundation of all life activities. In order to maintain this homeostasis, the organism must regulate the flux of the carbon skeletons arising from these fuel molecules in its diverse metabolic processes. A distortion of this flux could spell serious pathophysiological consequences for the organism. In this study, we observed a gradual increase in plasma and erythrocyte FFA in both male and female animals exposed to inorganic $\mathrm{Hg}$. While this increase was more in the female for plasma, it was more in the male for erythrocytes. This observation implies that inorganic $\mathrm{Hg}$ did not modulate the absorption of dietary lipids in both sexes. Rather, postabsorptive cellular lipid kinetics was the target of inorganic $\mathrm{Hg}$ toxicosis.

Circulating FFA are derived from the hydrolysis of triglycerides in the adipose tissue, with subsequent release into the plasma [41] which then equilibrates with the erythrocytes [42]. This hydrolysis is catalysed by adipose triglyceride lipase [43]. Generally, the release of FFA into the blood is stimulated to serve two purposes:

1. Meeting increased tissue demand for the synthesis of cholesterol, triglycerides, phospholipids, cholesterol esters, etc. for use either as structural cellular machinery or signalling molecules.

2. Covering energy requirements of various tissues.

Increased concentrations of plasma FFA suggests an imbalance between release and utilisation of plasma FFA. In higher animals, this imbalance in the flux of plasma FFA resulting in the elevation of this lipid is thought to occur secondary to psychological and physiological stress [44]. Recent experimental evidences indicate that exposure to inorganic $\mathrm{Hg}$ induces oxidative stress in exposed animals [8]. Thus, the observation of elevated plasma FFA in the inorganic Hg-exposed animals suggests a Hg-induced activation of adipose triglyceride lipase with the resultant increase in triglyceride hydrolysis, culminating in increased mobilisation of the FFA into the plasma which then equilibrates with that of the erythrocytes. Consistent with previous studies in humans [41], our findings (Fig. 7) indicate that lipolysis (rate of appearance of FFA in bloodstream) in rats is also sexually dimorphic. While this rate was greater in female animals than males for the plasma, the rate of equilibration of plasma FFA with erythrocyte FFA was greater in males than their female counterparts and that both phenomena were further perpetuated by inorganic $\mathrm{Hg}$ exposure. Further consequences of this sexually-induced pathological flux of circulating FFA in the animals can also be considered.

The distribution of circulating lipids between organs is mediated at the level of lipoprotein lipase (LPL), an enzyme located on the walls of blood capillaries of many tissues [45]. Expressed per cell, females have a higher LPL activity than males [46]. LPL catalyses the hydrolysis of plasma triglyceride carried in triglyceride-rich lipoproteins, chylomicrons and VLDL [47], yielding FFA and glycerol in the process. This hydrolysis determines the influx of FFA into tissues and the amount to be oxidised for fuel or esterified for storage, thus making LPL the node for the entry and re-esterification of FFA in those tissues $[48,49]$. Accumulation of FFA (as observed in this study) is known to inhibit LPL [50].
The downstream effects of LPL inhibition include severe hypertriglyceridemia (secondary to underutilisation of chylomicron and VLDL), hypocholesterolemia and decrease in HDL cholesterol and phospholipids [51]. Data in Figs. 2 and 3 however indicate that while hypocholesterolemia was observed in female animals on exposure to inorganic $\mathrm{Hg}$, plasma of male animals responded with hypercholesterolemia. Furthermore, while hypertriglyceridemia and decrease in HDL cholesterol were observed in both sexes. HDL phospholipid decreased in male animals, but increased only in female animals exposed to $1.5 \mathrm{mg}$ $\mathrm{Hg} / \mathrm{kg}$ body weight. Although the activity of LPL was not measured in this study, the "discrepancies" observed in the downstream effects of LPL inhibition between male and female animals on exposure to inorganic $\mathrm{Hg}$ suggest that LPL inhibition alone cannot account for the observed effects of inorganic $\mathrm{Hg}$. In view of the dyslipidemia observed in HDL (Fig. 3), the involvement of hepatic lipase cannot be ruled out, since this enzyme is known to hydrolyse triglycerides and phospholipids in the HDL, making the HDL remnant smaller, less dense, and hence pro-atherogenic [52]. Although it remains plausible that $\mathrm{Hg}$ could bind hepatic lipase to accentuate this sexual dimorphism in the downstream effects of LPL inhibition, experimental evidence in support of this proposition is yet lacking.

Uptake of FFA by tissues is normally stimulated by the signal transduced when there is a high concentration of circulating FFA [53, 54]. Uptake could be either by passive diffusion or via a protein-carrier-mediated pathway [55,56]. Protein carriers that have been characterised include fatty acid translocase (FAT/CD 36), plasma membrane fatty acid binding protein and fatty acid transport protein $[55,56]$.

Following uptake, the FFA are incorporated very rapidly into various lipid pools (phospholipids, triglycerides, cholesterol, cholesterol esters and diglycerides) with a portion serving as substrate for B-oxidation [47]. Data in Figs. 8 to10 indicate that inorganic $\mathrm{Hg}$ exposure not only modulated the uptake of FFA by the organs in a sexually dimorphic manner, the lipid pools arising from the utilisation of the FFA, as well as the intra-organ lipid kinetics, were also modulated by inorganic $\mathrm{Hg}$ exposure and this modulation also exhibited sexual dimorphism. While inorganic $\mathrm{Hg}$ did not inhibit the hepatic uptake of FFA in both sexes, the lipid pools arising from utilisation of FFA in each of the sexes differed. While the liver of male animals incorporated the FFA into the major lipids (cholesterol, triglyceride and phospholipid), their female counterparts incorporated the FFA into triglyceride and phospholipid with no evidence of cholesterol synthesis as female hepatic cholesterol remain unchanged. Furthermore, while there was a preponderance of cholesterol in the male hepatic lipid pool, a high concentration of phospholipid characterised the hepatic lipid pool of female animals exposed to inorganic Hg. There was no evidence of renal uptake of FFA by the female animals. Rather, exposure to inorganic $\mathrm{Hg}$ depleted the female kidney of its available triglyceride, suggesting that this lipid was hydrolysed to yield FFA which was then directed to B-oxidation. In contrast however, the slight uptake of FFA observed in male kidney was incorporated into triglyceride.

Pulmonary sexual dimorphism in lipid pool was characterised by cholesterogenesis and phospholipidosis in the male as compared to only pulmonary triglyceride constipation and depletion of phospholipid in the female lipid pool. Inorganic $\mathrm{Hg}$ did not inhibit cardiac uptake of FFA in both sexes as evidenced by the characteristics of the lipid pools in this organ - cholesterogenesis and triglyceride constipation in the female, whereas only triglyceride increased in the male. Evidence in support of a slight splenic FFA uptake by the female was provided by the transient phospholipidosis observed in the female spleen on exposure to $0.5 \mathrm{mg}$ $\mathrm{Hg} / \mathrm{kg}$ body weight whereas inorganic $\mathrm{Hg}$ inhibited FFA uptake by the male spleen as evidenced by the depletion of the lipid pool of this organ.

Coming after adipose tissue, the brain epitomises a tissue in mammals with both the highest lipid content and the highest diversity in the composition of these lipids [57]. Unlike the adipose tissue which largely stores FFA as triglycerides for subsequent utilisation and mobilisation to 
other peripheral tissues, the brain is thought to mainly utilise acylated lipids to generate phospholipids which are then incorporated into cell membrane elements [58]. Contrary to previously held theories, a number of studies has shown that FFA are able to cross the BBB and be transported into the brain from the systemic circulation $[59,60]$. Although the brain did not accumulate $\mathrm{Hg}$ to any appreciable extent in this study, the observation of depletion of brain cholesterol and phospholipid as a result of $\mathrm{Hg}$ exposure is consistent with alteration of the integrity of BBB via increased membrane permeability with subsequent leakage of these lipids from the brain [61]. Similar observation was also made by Teixeira et al. [8] using even a lower dose of inorganic $\mathrm{Hg}$. The $\mathrm{BBB}$ is rich in plasmalogens and the binding of $\mathrm{Hg}$ to these lipids with high affinity has been shown to alter their biophysical behaviour resulting in breakdown of their aggregates $[61,62]$.

One of the first targets of $\mathrm{Hg}$ upon absorption from the gastrointestinal tract are the red blood cells [61]. Lipidomic studies of these cells indicate that their membranes are also rich in plasmalogens [63, 64]. A similar alteration in their physico-chemical properties resulting in increased membrane permeability may also be assumed for the depletion of their lipids as a result of inorganic Hg exposure [62].

Although previous studies in humans showed that non-oxidative FFA clearance through re-esterification is higher in females than in males [9, 65], and thus suggesting that female tend to store whereas male tend to oxidise circulating FFA $[65,66]$, the characteristics as well as the kinetics of organ lipid pools in this study provide ample evidence that in both sexes, all the non-oxidative clearance of circulating FFA (reflected as triglyceride constipation and phospholipidosis), was induced by inorganic $\mathrm{Hg}$ exposure. These are hallmarks of inorganic Hg-induced lipotoxicity.

In order to prevent lipotoxicity, the hepatic tissue in each organism produces VLDL, incorporates into this lipoprotein the excess lipids and then secretes this lipid-rich VLDL into circulation [46,47]. Data in Fig. 4 indicate that while Hg did not inhibit the production of VLDL, the production of this lipoprotein did not keep pace with the increasing influx and esterification of FFA as evidenced by the altered lipid levels of the VLDL, thus allowing cholesterol, triglyceride and phospholipids to accumulate in the liver of male animals, but only triglyceride and phospholipids to accumulate in the liver of female animals which in turn resulted in fatty liver. Although in normal physiology the liver coordinates the metabolism of lipids to meet metabolic requirements, the molecular aspects of this biology are regulated by sex hormones (estrogens and androgens) in both male and female [46]. To what extent $\mathrm{Hg}$ influences the sex hormones (or vice versa) to modulate the molecular aspects of this hepatic lipid biology whose effects then reverberate in extra-hepatic tissues as observed in this study, remains to be elucidated.

The molar ratio of cholesterol to phospholipids is one of the indices of membrane fluidity [67,68]. An increase in this ratio indicates decreased fluidity while a decrease indicates increased fluidity $[68,69]$. Neither of this is desirable for the cell. However, $\mathrm{Hg}$ decreased this ratio in the brain of both sexes, decreased it in male heart, but increased it in female heart. Both increases and decreases were also observed in other organs. Several studies have associated changes in lipid/phospholipid profiles with impaired signal as well as energy transductions in heavy metal exposure [70,71]. Compelling accumulated and emerging experimental data from animal and human studies have shown a positive association between high circulating FFA and pathologies such as diabetes mellitus, thyrotoxicosis cardiovascular and pulmonary diseases [44,72-75]. Elevated pulmonary cholesterol has been shown to inhibit surfactant function by disrupting the physiology and turnover of surfactant, leading to impairment in lung mechanics [76]. Abnormalities in surfactant metabolism are the leading causes of acute respiratory distress syndrome, acute lung injury and a diverse array of other respiratory diseases [77]. Even though the biological roles of phospholipids are still not fully understood, depletion of these lipids in nervous tissue is associated with various neurodegenerative disorders including Alzheimer's disease and Down syndrome [78]. In Alzheimer's disease, phospholipids are specifically depleted in the areas of the brain showing degeneration and the prognosis of the disease is proportional to this phospholipid depletion [79]. Since $\mathrm{Hg}$ has been shown to play a role in Alzheimer's disease [80] and other pathologies [7], the observed lipotoxic and non-lipotoxic dyslipidemia in this study might be one of the incipient pathophysiological mechanisms underlying Hg-induced pathologies.

In conclusion, the findings of this study indicate that sexual dimorphism was the hallmark of the toxicokinetics and toxicodynamics of subchronic inorganic $\mathrm{Hg}$ exposure in the rat. While sexual dimorphism in $\mathrm{Hg}$ toxicokinetics was characterised by higher levels of $\mathrm{Hg}$ in female organs compared to males, the attendant toxicodynamics of $\mathrm{Hg}$ exposure reflected as lipotoxic and non-lipotoxic dyslipidemia, exhibited different patterns in both sexes. Since these different responses were observed with $\mathrm{Hg}$ concentrations that are environmentally relevant, our findings underscore the need to re-examine therapies directed at $\mathrm{Hg}$ as well as other metal intoxication in order to reflect both sexes and remove the currently held bias against the female sex. This may lead to developing novel sex-specific tailored treatment approaches to ameliorate the longterm metabolic risks associated with exposure to $\mathrm{Hg}$ and other metals in the general population.

\section{Declaration of competing interest}

The authors declare that they have no known competing financial interests or personal relationships that could have appeared to influence the work reported in this paper.

\section{Acknowledgements}

The technical assistance of Mr. O. A. Awoyemi, Mr. O. J. Olurinde, Mrs. J. O. Adebawa and Mrs. T. Osibanjo is greatly acknowledged.

\section{References}

[1] M. Gochfeld, Sex differences in human and animal toxicology, Toxicol. Pathol. 45 (2017) 172-189.

[2] D.J. Clegg, F. Mauvais-Jarvis, An integrated view of sex differences in metabolic physiology and disease, Mol. Metabol. 15 (2018) 1.

[3] R.M. Craft, Sex differences in drug- and non-drug-induced analgesia, Life Sci. 72 (2003) 2675-2688.

[4] M. Kogevinas, S.H. Zahm, Introduction: epidemiologic research on occupational health in women, Am. J. Ind. Med. 44 (2003) 563.

[5] J.C. Clifton, Mercury exposure and public health, Pediatr. Clin. North Am 54 (2007) 237-269.

[6] C.C. Bridges, R.K. Zalups, Transport of inorganic mercury and methylmercury in target tissues and organs, J. Toxicol. Environ. Health B Crit. Rev. 13 (2010) $385-410$

[7] J.D. Park, W. Zheng, Human exposure and health effects of inorganic and elemental mercury, J Prev Med Public Health 45 (2012) 344-352.

[8] F.B. Teixeira, A.C. de Oliveira, L.K. Leão, N.C. Fagundes, R.M. Fernandes, L. M. Fernandes, M.C. da Silva, L.L. Amado, F.E. Sagica, E.H. de Oliveira, Exposure to inorganic mercury causes oxidative stress, cell death, and functional deficits in the motor cortex, Front. Mol. Neurosci. 11 (2018) 125.

[9] J.B. Nielsen, O. Andersen, Transplacental passage and fetal deposition of mercury after low-level exposure to methylmercury-effect of seleno-L-methionine, J. Trace Elem. Electrolytes Health \& Dis. 6 (1992) 227-232.

[10] L.A. Broussard, C.A. Hammett-Stabler, R.E. Winecker, J.D. Ropero-Miller, The toxicology of mercury, Lab. Med. 33 (2002) 614-625.

[11] S. Doering, S. Bose-O'Reilly, U. Berger, Essential indicators identifying chronic inorganic mercury intoxication: pooled analysis across multiple cross-sectional studies, PLoS One 11 (2016), e0160323.

[12] C.A. Dooyema, A. Neri, Y.-C. Lo, J. Durant, P.I. Dargan, T. Swarthout, O. Biya, S. O. Gidado, S. Haladu, N. Sani-Gwarzo, Outbreak of fatal childhood lead poisoning related to artisanal gold mining in northwestern Nigeria, Environ. Health Perspect. 120 (2012) (2010) 601-607.

[13] D. Joshi, D.K. Mittal, S. Shukla, A.K. Srivastav, S.K. Srivastav, N-acetyl cysteine and selenium protects mercuric chloride-induced oxidative stress and antioxidant defense system in liver and kidney of rats: a histopathological approach, J. Trace Elem. Med. Biol. 28 (2014) 218-226.

[14] M.S. Trebucobich, M.H. Hazelhoff, A.A. Chevalier, S. Passamonti, A. Brandoni, A. M. Torres, Protein expression of kidney and liver bilitranslocase in rats exposed to mercuric chloride - a potential tissular biomarker of toxicity, Toxicol. Lett. 225 (2014) 305-310. 
[15] R.A. Bernhoft, Mercury toxicity and treatment: a review of the literature, J Environ Public Health 2012 (2012) 460508.

[16] S. Kalender, F.G. Uzun, F. Demir, M. Uzunhisarcıklı, A. Aslanturk, Mercuric chloride-induced testicular toxicity in rats and the protective role of sodium selenite and vitamin E, Food Chem. Toxicol. 55 (2013) 456-462.

[17] M. Carmignani, P. Boscolo, L. Artese, G. Del Rosso, G. Porcelli, M. Felaco, A. R. Volpe, G. Giuliano, Renal mechanisms in the cardiovascular effects of chronic exposure to inorganic mercury in rats, Occup. Environ. Med. 49 (1992) 226-232.

[18] L. Chehimi, V. Roy, M. Jeljeli, M. Sakly, Chronic exposure to mercuric chloride during gestation affects sensorimotor development and later behaviour in rats, Behav. Brain Res. 234 (2012) 43-50.

[19] S.X. Long, P.B. Hamilton, Y. Yang, S. Wang, W.D. Huang, C. Chen, R. Tao, Differential bioaccumulation of mercury by zooplankton taxa in a mercury contaminated reservoir Guizhou China, Environ. Pollut. 239 (2018) 147-160.

[20] O. Ademuyiwa, R. Agarwal, R. Chandra, J.R. Behari, Lead-induced phospholipidosis and cholesterogenesis in rat tissues, Chem. Biol. Interact. 179 (2009) 314-320.

[21] O.K. Afolabi, A.D. Wusu, O.O. Ogunrinola, E.O. Abam, D.O. Babayemi, O. A. Dosumu, O.B. Onunkwor, E.A. Balogun, O.O. Odukoya, O. Ademuyiwa, Arsenicinduced dyslipidemia in male albino rats: comparison between trivalent and pentavalent inorganic arsenic in drinking water, BMC Pharmacol. Toxicol. 16 (2015) 15.

[22] O. Ademuyiwa, R.N. Ugbaja, F. Idumebor, O. Adebawo, Plasma lipid profiles and risk of cardiovascular disease in occupational lead exposure in Abeokuta, Nigeria, Lipids Health Dis. 4 (2005) 19.

[23] P. Aja, E. Ekpono, J. Awoke, A. Famurewa, F. Izekwe, E. Okoro, C. Okorie, C. Orji, F. Nwite, B. Ale, Hesperidin ameliorates hepatic dysfunction and dyslipidemia in male Wistar rats exposed to cadmium chloride, Toxicol. Rep. 7 (2020) 1331-1338.

[24] C.-C. Kuo, P.-H. Su, C.-W. Sun, H.-J. Liu, C.-L. Chang, S.-L. Wang, Early-life arsenic exposure promotes atherogenic lipid metabolism in adolescence: a 15-year birth cohort follow-up study in central Taiwan, Environ. Int. 118 (2018) 97-105.

[25] M. Dieter, G. Boorman, C. Jameson, S. Eustis, L. Uraih, Development of renal toxicity in F344 rats gavaged with mercuric chloride for 2 weeks, or 2, 4, 6, 15, and 24 months, J. Toxicol. Environ. Health, Part A Current Issues 36 (1992) 319-340.

[26] K. Kostial, D. Kello, S. Jugo, I. Rabar, T. Maljković, Influence of age on metal metabolism and toxicity, Environ. Health Perspect. 25 (1978) 81-86.

[27] ATSDR, Toxicological Profile for Mercury, Agency for Toxic Substances and Disease Registry, Atlanta, GA, 2007.

[28] I.O. Banjoko, M.M. Adeyanju, O. Ademuyiwa, O.O. Adebawo, R.A. Olalere, M. O. Kolawole, I.A. Adegbola, T.A. Adesanmi, T.O. Oladunjoye, A.A. Ogunnowo, A. A. Shorinola, O. Daropale, E.B. Babatope, A.O. Osibogun, D.T. Ogunfowokan, T. A. Jentegbe, T.G. Apelehin, O. Ogunnowo, O. Olokodana, F.Y. Fetuga, M. Omitola, L.A. Okafor, C.L. Ebohon, J.O. Ita, K.A. Disu, O. Ogherebe, S.U. Eriobu, A. A. Bakare, Hypolipidemic effects of lactic acid bacteria fermented cereal in rats, Lipids Health Dis. 11 (2012) 170.

[29] O.A. Rotimi, I.O. Olayiwola, O. Ademuyiwa, E.A. Balogun, Effects of fibre-enriched diets on tissue lipid profiles of MSG obese rats, Food Chem. Toxicol. : Int. J. Publ. Br. Ind. Biol. Res. Assoc. 50 (2012) 4062-4067.

[30] J. Folch, M.a. Lees, S.G.H. Sloane, A simple method for the isolation and purification of total lipids from animal tissues, J. Biol. Chem. 226 (1957), 497-450.

[31] H.G. Rose, M. Oklander, Improved procedure for the extraction of lipids from human erythrocytes, J. Lipid Res. 6 (1965).

[32] S.E. Orr, C.C. Bridges, Chronic kidney disease and exposure to nephrotoxic metals, Int. J. Mol. Sci. 18 (2017) 1039.

[33] D.J. Thomas, H.L. Fisher, M.R. Sumler, A.H. Marcus, P. Mushak, L.L. Hall, Sexual differences in the distribution and retention of organic and inorganic mercury in methyl mercury-treated rats, Environ. Res. 41 (1986) 219-234.

[34] L. Friberg, Studies on the accumulation, metabolism and excretion of inorganic mercury (Hg203) after prolonged subcutaneous administration to rats, Acta Pharmacol. Toxicol. 12 (1956) 411-427.

[35] L. Magos, G.C. Peristianis, T.W. Clarkson, A. Brown, S. Preston, R.T. Snowden, Comparative study of the sensitivity of male and female rats to methylmercury, Arch. Toxicol. 48 (1981) 11-20.

[36] D.J. Munro, W.D. Gummer, Mercury accumulation in biota of thunder creek, Saskatchewan, Bull. Environ. Contam. Toxicol. 25 (1980) 884-890.

[37] P.M. Newberne, O. Glaser, L. Friedman, B.R. Stillings, Chronic exposure of rats to methyl mercury in fish protein, Nature 237 (1972) 40-41.

[38] J. Liu, R.A. Goyer, M.P. Waalkes, Toxic effects of metals, in: L.J. Casarett, J. Doull, C.D. Klaassen (Eds.), Casarett and Doull's Toxicology: the Basic Science of Poisons, seventh ed., McGraw-Hill, New York, 2008, pp. 931-979.

[39] Y. Muraoka, F. Itoh, Sex difference OF mercuric chloride-induced renal tubular necrosis IN rats: from the aspect of sex differences in renal mercury concentration and sulfhydryl levels, J. Toxicol. Sci. 5 (1980) 203-214.

[40] K.M. Rice, E.M. Walker Jr., M. Wu, C. Gillette, E.R. Blough, Environmental mercury and its toxic effects, J Prev Med Public Health 47 (2014) 74-83.

[41] B. Mittendorfer, Sexual dimorphism in human lipid metabolism, J. Nutr. 135 (2005) 681-686.

[42] S. Malhotra, D. Kritchevsky, Cholesterol exchange between the red blood cells and plasma of young and old rats, Mech. Ageing Dev. 4 (1975) 137-145.

[43] R. Zimmermann, J.G. Strauss, G. Haemmerle, G. Schoiswohl, R. BirnerGruenberger, M. Riederer, A. Lass, G. Neuberger, F. Eisenhaber, A. Hermetter, Fat mobilization in adipose tissue is promoted by adipose triglyceride lipase, Science 306 (2004) 1383-1386.

[44] E.A. Newsholme, C. Start, Regulation in Metabolism, John Wiley and Sons, Chichester, UK, 1981.
[45] I.J. Goldberg, C.M. Trent, P.C. Schulze, Lipid metabolism and toxicity in the heart, Cell Metabol. 15 (2012).

[46] B.T. Palmisano, L. Zhu, R.H. Eckel, J.M. Stafford, Sex differences in lipid and lipoprotein metabolism, Mol. Metabol. 15 (2018) 45-55.

[47] K.M. Botham, P.A. Mayes, Lipid transport and storage, in: V.W. Rodwell, D. A. Bender, K.M. Botham, P.J. Kennelly, W.P. A (Eds.), Harpers Illustrated Biochemistry 30th Edition, McGraw Hill Publishers, New York, 2015.

[48] J. Lee, I.J. Goldberg, Lipoprotein lipase-derived fatty acids: physiology and dysfunction, Curr. Hypertens. Rep. 9 (2007) 462-466.

[49] T. Pulinilkunnil, B. Rodrigues, Cardiac lipoprotein lipase: metabolic basis for diabetic heart disease, Cardiovasc. Res. 69 (2006) 329-340.

[50] J. Peterson, B.E. Bihain, G. Bengtsson-Olivecrona, R.J. Deckelbaum, Y. A. Carpentier, T. Olivecrona, Fatty acid control of lipoprotein lipase: a link between energy metabolism and lipid transport, Proc. Natl. Acad. Sci. U. S. A. 87 (1990) 909-913.

[51] D.J. Rader, Effects of nonstatin lipid drug therapy on high-density lipoprotein metabolism, Am. J. Cardiol. 91 (2003) 18E-23E.

[52] A.D. Pradhan, Sex differences in the metabolic syndrome: implications for cardiovascular health in women, Clin. Chem. 60 (2014) 44-52.

[53] K.L. Donnelly, C.I. Smith, S.J. Schwarzenberg, J. Jessurun, M.D. Boldt, E.J. Parks, Sources of fatty acids stored in liver and secreted via lipoproteins in patients with nonalcoholic fatty liver disease, J. Clin. Invest. 115 (2005) 1343-1351.

[54] P. Mermier, N. Baker, Flux of free fatty acids among host tissues, ascites fluid, and Ehrlich ascites carcinoma cells, J. Lipid Res. 15 (1974).

[55] K.G. Bharadwaj, Y. Hiyama, Y. Hu, L.A. Huggins, R. Ramakrishnan, N.A. Abumrad, G.I. Shulman, W.S. Blaner, I.J. Goldberg, Chylomicron- and VLDL-derived lipis enter the heart through different pathways: in vivo evidence for receptor- and nonreceptor-mediated fatty acid uptake, J. Biol. Chem. (2010) 285.

[56] G.D. Lopaschuk, J.R. Ussher, C.D.L. Folmes, J.S. Jaswal, W.C. Stanley, Myocardial fatty acid metabolism in health and disease, Physiol. Rev, 90 (2010).

[57] K. Bozek, Y. Wei, Z. Yan, X. Liu, J. Xiong, M. Sugimoto, M. Tomita, S. Paabo, C. C. Sherwood, P.R. Hof, J.J. Ely, Y. Li, D. Steinhauser, L. Willmitzer, P. Giavalisco, P. Khaitovich, Organization and evolution of brain lipidome revealed by largescale analysis of human, chimpanzee, macaque, and mouse tissues, Neuron 85 (2015) 695-702.

[58] J.A. Hamilton, K. Brunaldi, A model for fatty acid transport into the brain, J. Mol. Neurosci. : MN 33 (2007) 12-17.

[59] T.J. Tracey, F.J. Steyn, E.J. Wolvetang, S.T. Ngo, Neuronal lipid metabolism: multiple pathways driving functional outcomes in health and disease, Front. Mol. Neurosci. 11 (2018) 10.

[60] K.D. Bruce, A. Zsombok, R.H. Eckel, Lipid processing in the brain: a key regulator of systemic metabolism, Front. Endocrinol. 8 (2017) 60.

[61] E. Kerek, M. Hassanin, W. Zhang, E.J. Prenner, Preferential binding of Inorganic Mercury to specific lipid classes and its competition with Cadmium, Biochim. Biophys. Acta Biomembr. 1859 (2017) 1211-1221.

[62] S. Nakada, K. Inoue, S. Nojima, N. Imura, Change in permeability of liposomes caused by methylmercury and inorganic mercury, Chem. Biol. Interact. 22 (1978) 15-23.

[63] J.W. Farquhar, Human erythrocyte phosphoglycerides. I. Quantification of plasmalogens, fatty acids and fatty aldehydes, Biochim. Biophys. Acta 60 (1962) 80-89.

[64] E. Prenner, A. Sommer, N. Maurer, O. Glatter, R. Gorges, F. Paltauf, A. Hermetter, Lateral microheterogeneity of diphenylhexatriene-labeled choline phospholipids in the erythrocyte ghost membrane as determined by time-resolved fluorescence spectroscopy, J. Membr. Biol. 174 (2000) 237-243.

[65] O. Varlamov, C.L. Bethea, C.T. Roberts Jr., Sex-specific differences in lipid and glucose metabolism, Front. Endocrinol. 5 (2014) 241.

[66] A.P. Uranga, J. Levine, M. Jensen, Isotope tracer measures of meal fatty acid metabolism: reproducibility and effects of the menstrual cycle, American journal of physiology, Endocrinol. Metabol. 288 (2005) E547-E555.

[67] A. Abe, M. Hiraoka, J.A. Shayman, A role for lysosomal phospholipase A2 in drug induced phospholipidosis, Drug Metabol. Lett. 1 (2007) 49-53.

[68] C. Senault, J. Yazbeck, M. Goubern, R. Portet, M. Vincent, J. Gallay, Relation between membrane phospholipid composition, fluidity and function in mitochondria of rat brown adipose tissue. Effect of thermal adaptation and essential fatty acid deficiency, Biochim. Biophys. Acta Biomembr. 1023 (1990) 283-289.

[69] C. Bangur, J. Howland, S. Katyare, Thyroid hormone treatment alters phospholipid composition and membrane fluidity of rat brain mitochondria, Biochem. J. 305 (1995) 29-32.

[70] C. Exley, A molecular mechanism of aluminium-induced Alzheimer's disease? J. Inorg. Biochem. 76 (1999) 133-140.

[71] J.D. Pandya, K.R. Dave, S.S. Katyare, Effect of long-term aluminum feeding on lipid/phospholipid profiles of rat brain myelin, Lipids Health Dis. 3 (2004) 13.

[72] M. El Hafidi, I. Perez, S. Carrillo, G. Cardoso, J. Zamora, R. Chavira, G. Banos, Effect of sex hormones on non-esterified fatty acids, intra-abdominal fat accumulation, and hypertension induced by sucrose diet in male rats, Clin. Exp. Hypertens. 28 (2006) 669-681.

[73] T.L. Goodfreind, B.M. Egan, Nonesterified Fatty Acids in the Pathogenesis of Hypertension: Theory and Evidence, Prostaglandins, Leukotrienes, and Essential Fatty Acids, 1997, p. 57.

[74] E.M. Hafidi, R. Valdez, G. Baños, Possible relationship between altered fatty acid composition of serum, platelets, and aorta and hypertension induced by sugar feeding in rats, Clin. Exp. Hypertens. 22 (2000) 205-215.

[75] R.H. Unger, Lipotoxic diseases, Annu. Rev. Med. 53 (2002) 319-336. 
[76] B.R. Roszell, J.-Q. Tao, J.Y. Kevin, L. Gao, S. Huang, Y. Ning, S.I. Feinstein, C. H. Vite, S.R. Bates, Pulmonary abnormalities in animal models due to NiemannPick type C1 (NPC1) or C2 (NPC2) disease, PLoS One 8 (2013), e67084.

[77] M. Agassandian, R.K. Mallampalli, Surfactant phospholipid metabolism, Biochim. Biophys. Acta Mol. Cell Biol. Lipids 1831 (2013) 612-625.

[78] P. Brites, H.R. Waterham, R.J. Wanders, Functions and biosynthesis of

plasmalogens in health and disease, Biochim. Biophys. Acta Mol. Cell Biol. Lipids 1636 (2004) 219-231.
[79] X. Han, D.M. Holtzman, D.W. McKeel Jr., Plasmalogen deficiency in early Alzheimer's disease subjects and in animal models: molecular characterization using electrospray ionization mass spectrometry, J. Neurochem. 77 (2001) 1168-1180.

[80] J. Mutter, A. Curth, J. Naumann, R. Deth, H. Walach, Does inorganic mercury play a role in Alzheimer's disease? A systematic review and an integrated molecular mechanism, J. Alzheim. Dis. 22 (2010) 357-374. 